\title{
Recursion and the Definition of Universal Prosodic Categories
}

\author{
Lisa Lai-Shen Cheng ${ }^{1}$ and Laura J. Downing ${ }^{2, * \mathbb{D}}$ \\ 1 Leiden University Centre for Linguistics, Leiden University, 2311 BE Leiden, The Netherlands; \\ 1.1.cheng@hum.leidenuniv.nl \\ 2 Department of Languages and Literatures, University of Gothenburg, 40530 Gothenburg, Sweden \\ * Correspondence: downinglauraj@gmail.com
}

check for updates

Citation: Cheng, Lisa Lai-Shen, and Laura J. Downing. 2021. Recursion and the Definition of Universal Prosodic Categories. Languages 6: 125. https://doi.org/10.3390/ languages6030125

Academic Editors: Ingo Feldhausen, Caroline Féry and Frank Kügler

Received: 5 January 2021

Accepted: 5 July 2021

Published: 26 July 2021

Publisher's Note: MDPI stays neutral with regard to jurisdictional claims in published maps and institutional affiliations.

Copyright: (c) 2021 by the authors. Licensee MDPI, Basel, Switzerland. This article is an open access article distributed under the terms and conditions of the Creative Commons Attribution (CC BY) license (https:// creativecommons.org/licenses/by/ $4.0 /)$.

\begin{abstract}
It is widely agreed that prosodic constituents should mirror syntactic constituents (unless high-ranking prosodic constraints interfere). Because recursion is a feature of syntactic representations, one expects recursion in prosodic representations as well. However, it is of current controversy what kinds of syntactic representation motivate prosodic recursion. In this paper, the use of Phonological Phrase recursion is reviewed in several case studies, chosen because prosodic recursion mostly does not reflect syntactic recursion as defined in current syntactic theory. We provide reanalyses that do not appeal to prosodic recursion (unless syntactically motivated), showing that Phonological Phrase recursion is not necessary to capture the relevant generalizations. The more restrictive use of prosodic recursion we argue for has the following conceptual advantages. It allows for more consistent cross-linguistic generalizations about the syntax-prosody mapping so that prosodic representations more closely reflect syntactic ones. It allows the fundamental syntactic distinctions between clause (and other phases) and phrase to be reflected in the prosodic representation, and it allows cross-linguistic generalizations to be made about the prosodic domain of intonational processes, such as downstep and continuation rise.
\end{abstract}

Keywords: Intonation Phrase; Phonological Phrase; Akan; Bàsàá; Basque; Chimwiini; Connemara Irish; Kimatuumbi; phase-based domains

\section{Introduction}

Selkirk (2011, pp. 439-40) sets forth the following principles defining what Ito and Mester (2013) call the Syntax-Prosody Mapping Hypothesis (SPMH):

(1) a. The constituent structures of syntax and prosody correspond. The theory predicts a strong tendency for prosodic domains to mirror syntactic constituents.

b. There is a strong tendency to recursivity as the result of syntactic constituency-respecting correspondences between syntax and prosody.

c. In the ideal case, the grammar allows the fundamental syntactic distinctions between clause, phrase, and word to be reflected in, and retrieved from, the phonological representation.

d. Phonological markedness constraints on prosodic structure, if high-ranked, may produce instances of non-isomorphism between syntactic constituency and prosodic domain structure.

In this paper, we take a closer look at Principle (1b), namely, how the requirement that prosodic constituency should mirror syntactic constituency (Principle (1a)) straightforwardly motivates prosodic recursion. While this effect is clearly demonstrated in work adopting the SPMH framework, such as Cheng and Downing (2016), Féry (2016), and Selkirk (2011), recursion still violates a well-formedness constraint on prosodic structure, NORECURSION (Ito and Mester 2012; Selkirk 1995; Vigário 2010; Vogel 2009, 2012, 2019). It thus bears investigating under what conditions prosodic recursion can be considered well-formed. 
We assume that in the default case, prosodic recursion is only well-formed when constraints mapping prosodic structure to syntactic structure derive that result as optimal because the syntactic structures that are the target of the parse are recursive (and these mapping constraints outrank NORECURSION). However, the question arises which syntactic structures qualify as recursive in current syntactic theory. Elordieta (2015), for instance, suggests: "Since one syntactic phrase may dominate another phrase, a natural assumption in this theory is that recursion is regular in prosodic structure as well." (p. 58) This assumes that (a) phonology does not make a distinction between different XPs, as long as they are phrases, and (b) nothing other than phrase-hood is relevant to the syntax-phonology mapping. This furthermore takes XP-domination as the basis of prosodic recursion and makes the syntactic structure as a whole a mass aggregation of recursion, a move that not only is not compatible with typical syntactic definitions of recursion (see discussion of Karlsson 2010 in Section 2.1, below) but also ignores the well-motivated distinctions between the types of syntactic constituents that match the Intonation Phrase and the types that match the Phonological Phrase as defined in work such as Ito and Mester $(2012,2013)$, Selkirk (2011, p. 453ff), and Truckenbrodt (1995, 1999, 2007).

In this paper, we evaluate more specifically proposals that appeal to Phonological Phrase recursion, beginning with its use since Truckenbrodt $(1995,1999)$ as a way to parse the Larsonian VP. In some recent analyses, such as Elfner (2015) and Elordieta (2015), Phonological Phrase recursion has even been used to parse the clause, thus abandoning the principle, cited in (1c) above, which requires, as the unmarked case, that the distinction between phrase and clause should be reflected in the prosodic representation (see, e.g., Ito and Mester 2013; Nespor and Vogel 1986; Selkirk 2009, 2011; Truckenbrodt 1995, 1999, 2007). Our critique of these uses of Phonological Phrase recursion is structured as follows. In Section 2, we define syntactic recursion, highlighting differences between Larsonian and modern phasal syntactic structures, and then we discuss the implications of the differences for prosodic mapping. In Section 3, we discuss cases mainly from African languages, showing that Phonological Phrase recursion has often been adopted to parse syntactic domains that are best reanalyzed as corresponding to Intonational Phrases. In Section 4, we reanalyze two cases from European languages where even the clause has been parsed as a Phonological Phrase. Section 5 concludes.

\section{Syntactic Recursion and Syntax-Prosody Mapping}

\subsection{Syntactic Recursion and Recursive Spell-Outs}

To understand the theoretical and conceptual consequences of the syntax-prosody mapping and how the mapping of recursive syntactic structures can lead to prosodic recursion, it is important to define what syntacticians understand a recursive structure to be. Karlsson (2010) makes a clear distinction between syntactic recursion due to embedding and syntactic iteration: "recursion builds structure by increasing embedding depth, whereas iteration yields flat output structures, repetitive sequences on the same depth level as the first instance" (p. 45). We illustrate this distinction with the following English sentences:

(2) a. Sydney thinks [ $\mathrm{CP} 1$ that Robin believes [ $\mathrm{CP} 2$ that Charlie won the competition]].

b. Robin saw the essay [ CP1 $_{\text {that }}$ thydney wrote for the department [ ${ }_{\mathrm{CP} 2}$ which hired Charlie]].

(3) a. Charlie [[[went] $]_{\mathrm{VP} 1}$ quickly] $]_{\mathrm{VP} 2}$ by train $\left.]_{\mathrm{VP} 3}\right]$.

b. That was [DP a [NP nice [NP1 beautiful [NP2 sunny [NP3 day]]]]].

The sentences in (2) are clear examples of recursion, where the recursive $\mathrm{CP}$ yields extra (self-) embedding. (2a) involves a typical embedding involving verbs that select for complement clauses. (2b) involves noun phrases with relative clauses, with the first relative clause $\left(\mathrm{CP}_{1}\right)$ containing another noun phrase with a relative clause $\left(\mathrm{CP}_{2}\right)$. These are also cases of nested structures. (3a,b), on the other hand, are edge additions, which, depending on your structural assumptions, can be considered to be iterations rather than recursive structures. ${ }^{1}$ Another case of potential recursion concerns the so-called VP-shell structures 
(Larson 1988), which have often been used to analyze double complement sentences or sentences involving a PP-goal, such as those in $(4 a, b)$.

(4) a. Nora gave a sweater [PP to Sydney].

b. Nora gave Sydney a sweater.

The structure in (5a), below, is the Larsonian structure for dative PPs, as in (4a), and (5b) is a structure that is often used post-Larson (1988) for double object complements, as in (4b). ${ }^{2}$ In both (5a) and (5b), the higher V selects for another VP, leading to a typical recursive structure, one that involves "self-embedding" (see Nevins et al. 2009).

(5)
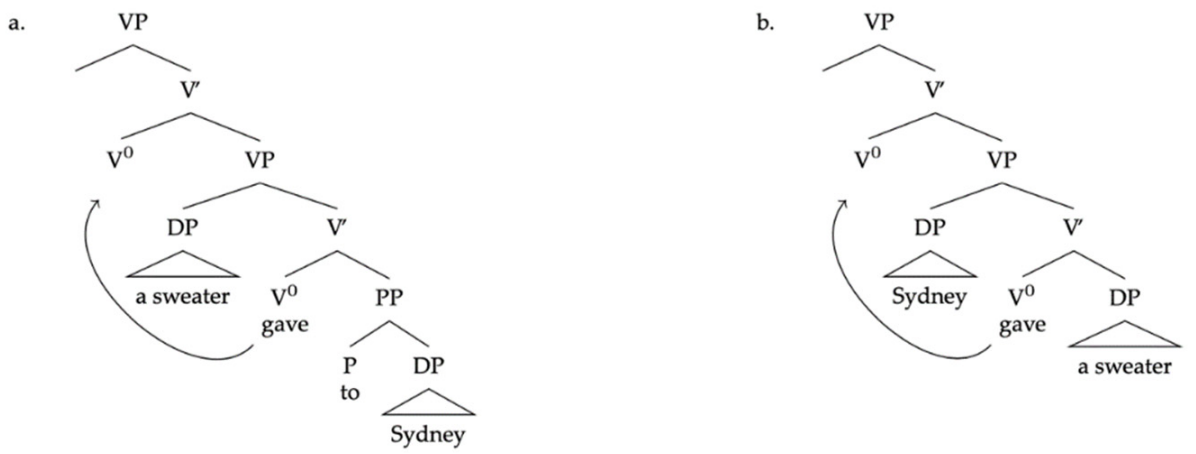

It should be noted that even works in the pre-Minimalist Program era do not consider there to be recursion between the PP and the VPs or between the DP Sydney and the PP in (5a). In both cases, we have clear-cut domination of phrase markers. However, these involve different categories, and thus there is no recursive embedding involved. ${ }^{3}$ Indeed, if syntactic domination between XPs were considered a form of recursion, then there would never have been any controversy concerning whether Pirahã constitutes an exception to the claim that syntactic recursion is a defining property of human language (see Nevins et al. 2009).

Since the Minimalist Program (Chomsky 1995), the Larsonian view of double object structures has been called into question (see, e.g., Beck and Johnson 2004, as well as the overview article by Citko et al. 2017). More updated structures are given in $(6 \mathrm{a}, \mathrm{b})$. The structure in (6a) reflects the possessive relation between the two objects, represented by a small clause-like structure (i.e., the PP is a small clause, see Harley 2002). (6b) retains roughly the idea that the two objects are in one XP (small clause), with a subject-predicate relation.

(6)
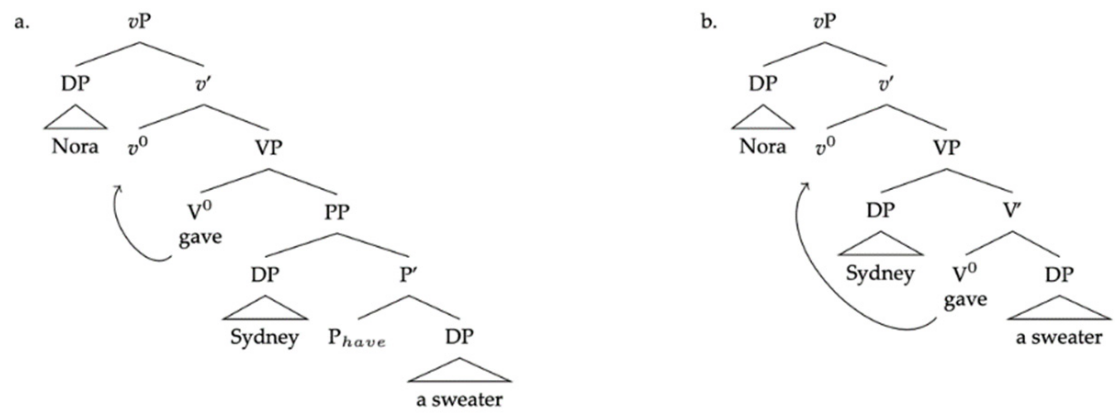

Note that neither (6a) nor (6b) are recursive structures (not even forms of "selfrecursion"), as there are no multiple layers of VP. Furthermore, it is important to note that the node that dominates the verb and its objects, $v \mathrm{P}$, is not considered to be a lexical 
projection (see Chomsky 1995 and subsequent work). ${ }^{4}$ In short, in contrast to the Larsonian representations in (5), in current syntactic theory, VP-recursion does not characterize double object cases like those represented in $(6 a, b)$.

Chomsky (2001) makes it very clear that syntactic derivation is cyclic and that the phonological cycle is not an independent cycle. In formal terms, derivations proceed in phases. When the derivation reaches a phase, it is handed over (spelled-out) to the phonological component (and the semantic component). ${ }^{5}$ Chomsky (2001) considers both $v \mathrm{P}$ and $\mathrm{CP}$ to be phases (and DP is a potential phase). In other words, during a derivation of a sentence involving an embedded clause like (2a) (structure in (7a)), there is a recursive process of phasal spell-out. In the literature, the recursive process of phasal spell-out is called "multiple spell-out" (see Epstein et al. 1998, Uriagereka 1999 and Chomsky 2000). In (7a), the $v \mathrm{P}$-phase of the embedded clause will first go through phasal spell-out where it is transferred to the phonological component. The next spell-out cycle is the embedded $\mathrm{CP}$ phase, and so on. The structure in (7b) indicates the structure of a noun phrase with a relative clause (like the sentence in (2b)), under a Kaynian analysis of relative clauses (Kayne 1994). As we can see in (7b), this yields phases embedded inside the DP (plus two additional phases are inside the DP the department which hired Charlie) and thus recursive phasal spell-out.

(7)

a.

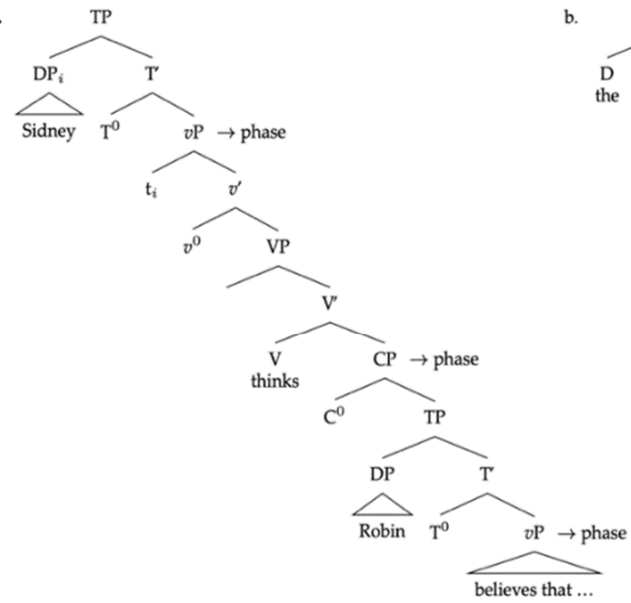

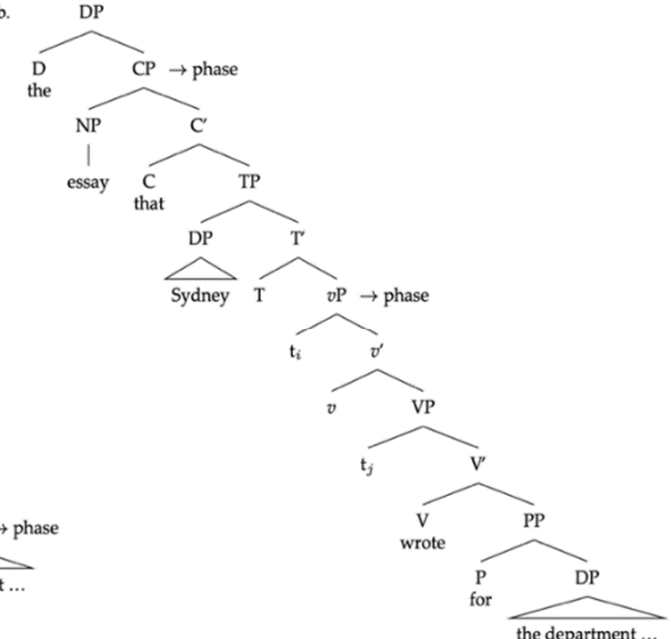

The structure in (8) gives the complete representation of a sentence including both a direct and an indirect object. As we have seen in (6), the verb and both objects are within the $v \mathrm{P}$, belonging to the $v \mathrm{P}$-phase, and the whole sentence is another phase, $\mathrm{CP}$. Given the structure in (8), a sentence involving a direct object and an indirect object has two phasal spell-outs. 
(8)

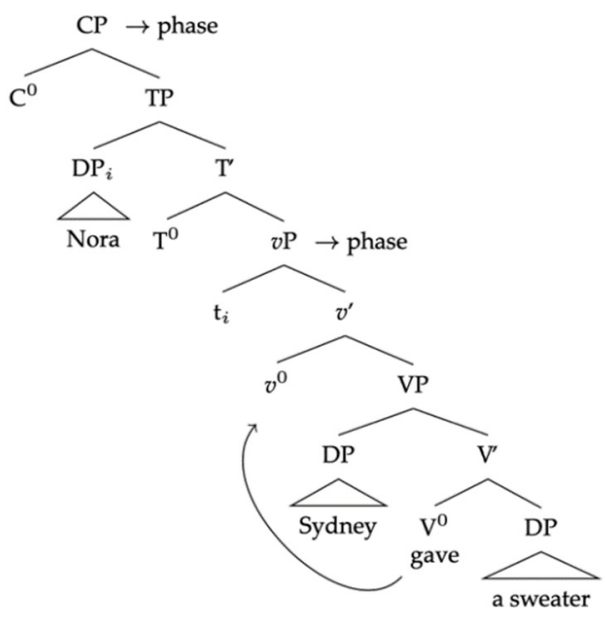

Kratzer and Selkirk (2007) were among the first to adopt a phasal spell-out approach to syntax-prosody mapping within the SPMH framework (see also Ishihara (2007)). If phases indeed play a role in syntax-prosody mapping, we need to consider the implications phasal syntax has for prosodic recursion. We have seen that in narrow syntax, we have a process of phasal spell-out, which is by definition recursive. In other words, within the minimalist framework, the phonological component is built up cyclically based on the phasal spell-outs. It thus follows that recursive prosodic structure building is motivated by recursive phasal spell-outs in an interface theory like SPMH (1), where prosodic structure mirrors syntactic structure. We demonstrate this formally in the next section.

\subsection{Mapping Prosodic Structure with Syntactic Structure}

We follow work such as Bennett and Elfner (2019), Féry (2016), Hamlaoui and Szendroï (2015), Ito and Mester (2012, 2013), Nespor and Vogel (1986), Selkirk (2009, 2011), and Truckenbrodt $(1995,1999,2007)$ in assuming the following universal syntax-prosody correspondences:

(9) Syntactic category Clause $(\mathrm{CP})$

Prosodic category lexical XP Intonation Phrase ( $\iota$ ) Phonological Phrase $(\varphi)$

As Ito and Mester $(2012,2013)$ and Selkirk (2011) make especially clear, it is of central theoretical importance to explicitly define the syntactic constituents that correspond to each prosodic category, as otherwise meaningful cross-linguistic comparisons of the phonological and phonetic properties of the Phonological Phrase and Intonation Phrase are not possible. We refine the definitions of the relevant syntactic categories in (9) in two ways. First, we adopt Cheng and Downing's $(2007,2009,2016)$ proposal that phasebased domains-e.g., not only $\mathrm{CP}$ but also $v \mathrm{P}$-correspond to the prosodic category of the Intonation Phrase ( $)$. This proposal finds motivation in Chomsky's (2004, p. 124) suggestion that, semantically, it is natural to think that both $v \mathrm{P}$ and $\mathrm{CP}$ are phases because they are both "propositional constructions." Propositional constructions are the constituents that most naturally correspond to the Intonation Phrase. As we saw in the preceding section, CP-internal phases stand in a syntactic embedding and recursion relationship with $\mathrm{CP}$, and this provides an additional motivation for mapping them to the same prosodic constituent as CP. In addition, we adopt Féry's (Féry 2011, p. 1909) proposal that the Phonological Phrase maps XP arguments. We assume that the distinction between lexical $X P s$ vs. functional XPs defines a crucial distinction between the types of constituents that the Phonological Phrase vs. Intonation Phrase can correspond to, following work such as Truckenbrodt (2007) and Selkirk (2011, p. 453). Since $v$ P is a not a lexical category, this provides yet another motivation for not mapping it to the Phonological Phrase, but rather to the Intonation Phrase. Finally, like most of the work cited in this paper, we assume that the syntax-prosodic correspondence in (9) is formally expressed using mutual ALIGNL/R 
or MATCH constraints, which evaluate the mapping between specific prosodic constituents and specific syntactic ones and, by default, are high-ranked.

Syntax is not the only factor defining the parse into prosodic constituents. From the earliest literature on the phonology-syntax interface (e.g., Nespor and Vogel 1986, Selkirk 1986), it has been demonstrated that the mapping of prosodic structure with syntactic structure is not perfect, i.e., there are mismatches and adjustments, motivated by prosodic principles, which are characterized by some (e.g., Hulst 2010, p. 304) to involve "flattening" of the structure. Based on an analysis of prosodic phrasing in Zulu (Bantu S.42, South Africa), we examine next what type of recursive prosodic structures we expect if we have relatively close mapping between phasal spell-outs and prosodic constituents, also drawing attention to mismatches.

We begin with examples from Zulu that illustrate a partial mapping between phases and $\iota$. The consistent prosodic correlate of $\iota$ in Zulu is phrase penultimate vowel lengthening. As Cheng and Downing $(2007,2009,2016)$ show, only the right edge of the phase defines a right $\iota$ boundary, as this is the locus of phonological cues to prosodic structure. This is shown in $(10 a, b)$, where curly brackets indicate $\iota$ boundaries and an acute accent indicates a High tone. In $(10 \mathrm{a}, \mathrm{b})$, we have not indicated the $v \mathrm{P}$-phase boundary, as it coincides with the CP-phase boundary at the right edge:
a. $\left.\quad\{\text { [úm-fúndísi ú-fúndel-ê: ábá-zal' ín-cwa:di] }]_{\mathrm{CP}}\right\}_{\mathrm{L}}$
1-teacher 1-read.to-PERF 2-parent 9-letter
'The teacher read to the parents a letter.'

\section{b. \{[ú-Síph' ú-fún' [úkúth' ú-Thándi á-théng' í-bhayiséki:li] $\left.\left.\left.]_{\mathrm{CP}}\right]_{\}_{\mathrm{L}}}\right]_{\mathrm{CP}}\right\}_{\mathrm{L}}$ 1-Sipho 1-want that 1-Thandi 1-buy 5-bicycle} 'Sipho wants Thandi to buy a bicycle.'

The prosodic phrasing in (10b) and (11), which parses the entire sentence into a single l, further shows that the left-edge of each syntactic phase does not correlate with a prosodic boundary in Zulu. A separate constraint-and an assumption of exhaustive parsing-is responsible for the left-edge alignment of $\iota$ only with the outermost CP (i.e., root clause or illocutionary clause in Selkirk's $(2005,2011)$ terminology), leading to a mismatch between syntactic phases and prosodic constituents. This is shown schematically in (11), which includes the $v$ P-phase boundaries.

$$
\left.\left.\left\{\left[\left[_{\mathrm{CP}} \text { subject } \quad\left[{ }_{\nu \mathrm{P} \text { verb }} \quad\left[\mathrm{CP} \text { that subject } \quad\left[{ }_{\nu \mathrm{P} \text { verb }} \text { object }\right]\right\}\right]\right\}\right]\right\}\right]\right\}
$$

That is, even though each $v \mathrm{P}$ and each $\mathrm{CP}$ are syntactic phases, only the right edge of each of these phases is correlated with the prosodic cues, which condition an ı boundary in this analysis (see Cheng and Downing 2016 and Bonet et al. 2019 for detailed discussion of this kind of edge asymmetry in Zulu and other Bantu languages).

The syntax-prosody mapping algorithm that we are motivating here builds upon the notion of phasal spell-outs. Regardless of whether the mapping is done cyclically, with the prosodic cycle embedded in the syntactic cycle, it is clear from the Zulu data that the phase is the constituent that is mapped to ı's. Since phasal spell-out is a recursive process, as explained in the preceding section, the prosodic structure building necessarily leads to recursive ı's if the prosody-syntax mapping constraints outrank NORECURSION. ${ }^{6}$ What is further evident from (10) is that the mapping has an edge bias, which is further supported by sentences with a relative clause in the subject noun phrase like (12a), where the phrasing contrasts with that of sentences with a relative clause in the object noun phrase like (12b). Note that penult vowel lengthening is found at the right edge of each phase while there continue to be no prosodic cues to the left edge of each phase. This is particularly evident in the case of object relative clauses, as in (12b). That is, these data show that the recursive ı's that parse the phases $(\mathrm{CP}$ and $v \mathrm{P})$ can have recursive prosody at the right edge but not at the left: 
(12)

$\begin{array}{lllll}\text { a. }\{[\text { úm-fúndísi } & \text { [ó-thól-ê: } & \left.\text { ín-dánda:tho }]_{\mathrm{CP}}\right\}_{\mathrm{L}} & \text { ú-zo-thóla } & \left.\text { úm-klóme:lo] }]_{\mathrm{CP}}\right\}_{\mathrm{L}} \\ \text { 1-teacher } & \text { REL.1-find-PERF } & \text { 9-ring } & \text { 1-FUT-get } & \text { 3-rewards }\end{array}$

'The teacher who found the ring will get a reward.'
b. $\{[$ si-phul'
[ím-baz'
é-théngw-é
we-break
9-axe
REL.9-be.bought-PERF
námhlâ:nje] CP ) \} $\left.{ }_{\llcorner C P}\right\}_{\llcorner}$
'We broke the axe that has been bought today.'
today

Assuming the raising analysis of relative clauses (e.g., Kayne 1994), Cheng and Downing (2007) show that (a) the head-noun of a relative clause phrases prosodically with the relative clause; (b) only the right-edge of the $\mathrm{CP}$ phase conditions an ı boundary, and (c) in Zulu (as in many other languages), the DP does not have a phasal status. ${ }^{7}$ This is confirmed by the lack of any prosodic cues motivating a corresponding $\iota$ boundary associated with DPs (also in $(10 a, b))$. Note again that the relative clauses and the matrix clauses in $(12 a, b)$ have recursive $\iota$ boundaries (mirroring recursive $C P$-phasal spell-outs as well as recursive vP-phasal spell-outs).

The constraints and tableau below, adapted from Cheng and Downing (2016), formalize the analysis. The relevant syntactic category to capture the generalizations for Zulu is the phase. Following the universal syntax-prosody correspondence principles discussed for (9), the phase maps to the Intonation Phrase. The edge asymmetry is captured by asymmetric alignment constraints: the right edge of every phase maps to an $\iota$, to satisfy $(13 a, b)$, while only the left edge of the root clause maps to $\iota$, to satisfy $(13 c, d) .8$

(13) a. AlignR[Phase, IntPh] (AlignR-Phase): Align the right edge of every phase $(v \mathrm{P} / \mathrm{CP})$ with the right edge of an Intonation Phrase (IntPh).

b. AlignR[IntPh, Phase] (AlignR-IntPh): Align the right edge of every Intonation Phrase (IntPh) with the right edge of a phase ( $v \mathrm{P} / \mathrm{CP})$.

c. AlignL[IntPh, Root CP] (AlignL- IntPh): Align the left edge of every Intonation Phrase with the left edge of a Root $\mathrm{CP}$.

d. AlignL[CP, IntPh] (AlignL-Root CP): Align the left edge of every root CP with the left edge of an Intonation Phrase.

The tableau in (14) exemplifies the analysis of a sentence like (12a); only crucial constraints are included for clarity of exposition. Note that the syntax-prosody mapping constraints are, by default, equally high-ranked:

\begin{tabular}{|c|c|c|c|c|c|}
\hline (14) & [úm-fúndísi [ó-thól-ê: ín-dánda:tho]cr ú-zo-thóla úm-klóme:lo] ст & $\begin{array}{l}\text { ALIGNL- } \\
\text { INTPH }\end{array}$ & $\begin{array}{c}\text { ALIGNR- } \\
\text { PHASE }\end{array}$ & $\begin{array}{l}\text { ALIGNR- } \\
\text { INTPH }\end{array}$ & $\begin{array}{c}\text { No } \\
\text { RECUR- } \\
\text { SION }\end{array}$ \\
\hline a. & {$\left[\begin{array}{c}\text { [úm-fúndísi [ó-thól-ê: ín-dánda:tho]cP ú-zo-thóla úm-klóme:lo] cP } \\
\{\end{array}\right\}$} & & & & $*$ \\
\hline b. & [úm-fúndísi [ó-thól-ê: ín-dánda:tho]cr ú-zo-thóla úm-klóme:lo] & & $* !$ & & \\
\hline c. & [úm-fúndísi [ó-thól-ê: ín-dánda:tho]cr ú-zo-thóla úm-klóme:lo] cP & $* !$ & & & \\
\hline
\end{tabular}

Candidate (14a) is optimal, as it only violates low-ranked NORECURSION, the constraint penalizing recursive prosodic structure (Selkirk 1995; Truckenbrodt 1995, 1999). As we can see in this candidate, ranking ALIGNR above NORECURSION optimizes recursive prosodic structure to mirror recursive syntactic structure. While Candidates $(14 \mathrm{~b}, \mathrm{c})$ satisfy NoRECURSION, Candidate $(14 \mathrm{~b})$ is non-optimal, as the right phase edge following the relative clause does not map to the right edge of $\iota$. Candidate (14c) is non-optimal, as it contains a left $\iota$ constituent edge that does not map to the left edge of a root/illocutionary CP. Cheng and Downing (2016) show that this approach straightforwardly accounts for prosodic phrasing of relative clauses, in particular, not only in Zulu but also in other languages, leading to analyses where prosodic recursion is justified by syntactic recursion as defined in Section 2.1. ${ }^{9}$ 
All of the examples from Zulu that illustrate nested, embedded recursion in the syntax lead to recursive prosodic structure at the level of the Intonation Phrase ( $($ ). We turn now to analyses appealing to recursion in prosodic units smaller than $\iota$, namely, the Phonological Phrase $(\varphi)$. A striking case that appears to motivate recursive $\varphi$ structure is the assignment of final High tone in Chimwiini (Bantu G.412, Somalia), as demonstrated in Kisseberth $(2005,2010 a, 2010 b, 2017)$. Consider first the examples in $(15 a, b)$ from Kisseberth (2010a, pp. 225-27), where we see that by default all Phonological Phrases in Chimwiini, defined as in (9), are realized with a High tone on the phrase penult syllable. ${ }^{10}$

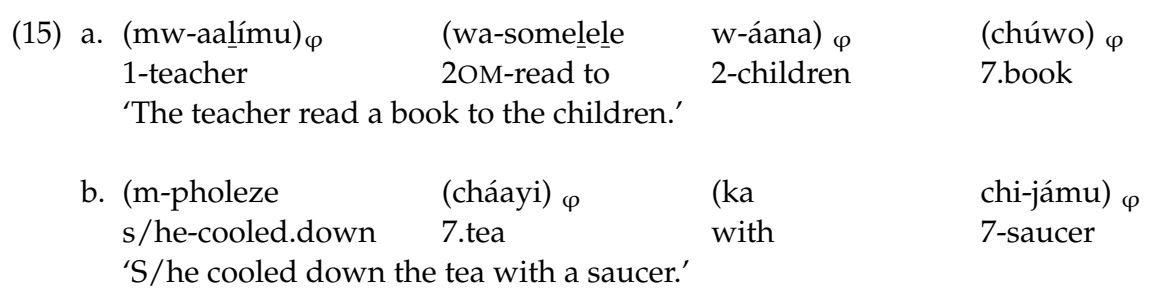

Sentences in (16a-d), below, from Kisseberth (2005, pp. 142-43) illustrate cases with first and second person subject prefixes on the verb, rather than third person subject prefixes, as in the above examples. As we can see, these subject prefixes trigger a final High tone rather than a penult High tone: compare the sentences in $(16 a, b)$. These examples also show that the High tone motivated by the morphology of the verb is realized on the final word of the Phonological Phrase containing the verb, not on the verb itself. Note in (16a) that a verb with a third-person subject prefix triggers the default penult High tone realization in the Phonological Phrase, just as the default cases we see in $(15 a, b)$. Strikingly, in both (16c) and (16d), we see that each verbal complement is realized with a final High tone. Kisseberth accounts for this, as shown in (16c), by proposing that the indirect object and the direct object are recursively parsed into a $\varphi$ that includes the triggering verb, and in (16d), the instrumental phrase is also recursively parsed into a $\varphi$ that includes preceding verbal complements as well as the triggering verb:

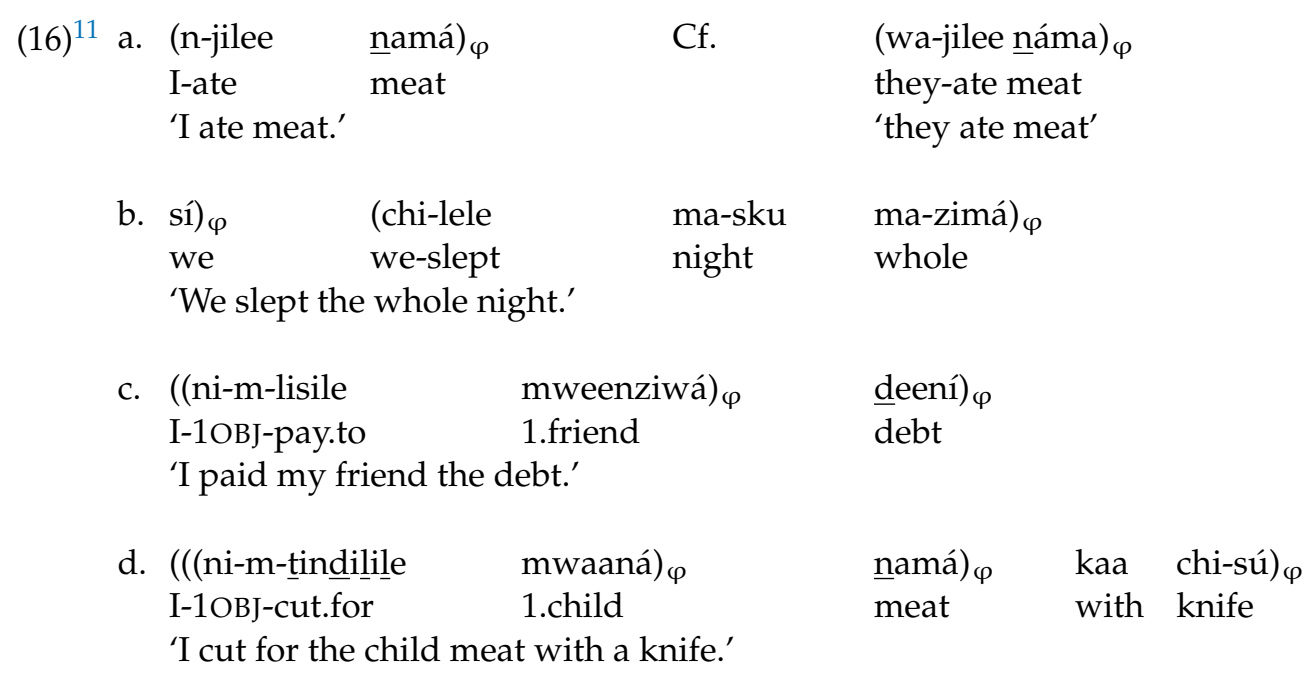

In Kisseberth $(2005,2010 a, 2010 b, 2017)$ analysis, the domain of final High tone assignment in Chimwiini is the recursive $\varphi$ that contains the triggering verb. Kisseberth accounts for the repeated assignment of the final High tone as follows. As shown in (16), recursive $\varphi$ structure allows the triggering verb to be contained in all of the $\varphi^{\prime} s$ that realize the final High tone. Repeated occurrences of the final High tone are accounted for by assigning a High tone to the final syllable of every recursion of the $\varphi$ that contains the triggering verb. This might be considered a form of High tone agreement.

An alternative analysis, which does not rely on prosodic recursion of $\varphi$, is provided if we consider the simplified syntactic structure of (16d) in (17). We assume that verbs in Chimwiini, such as verbs in other Bantu languages, raise to a position higher than $v \mathrm{P}$, but 
lower than TP (see Julien 2002 among others). In (17), the verb has moved via $v^{0}$ and the head of the Applicative Phrase $\left(\mathrm{Appl}^{0}\right)$ to a higher head below T ${ }^{0}$, indicated as $\gamma^{0}$, which hosts the final vowel, expressing aspectual or mood information.

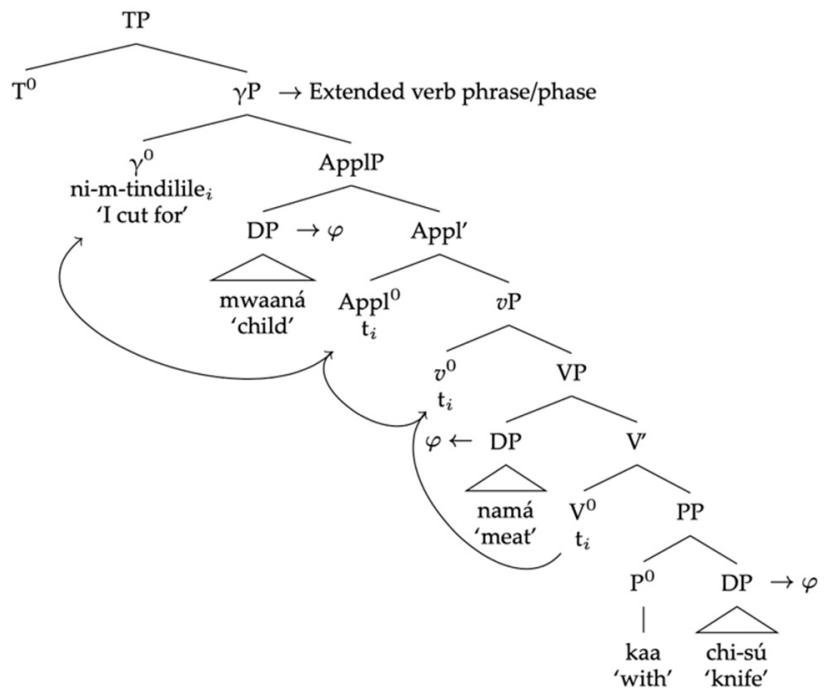

As indicated in (17), each DP argument maps to a $\varphi$. The apparently recursive nature of final High tone assignment in this analysis continues to follow from requiring each $\varphi$ within the domain of the triggering verb to be realized with a High tone on the final syllable. However, in this alternative analysis, the domain of the final High tone assignment does not follow from syntactic or prosodic recursion, as each DP argument is parsed in an independent prosodic domain. Our alternative analysis is based on the observation that, in structures like in (17), the verb has moved up to $\gamma^{0}$ via the phasal head $v^{0}$, and the domain of the $v \mathrm{P}$-phase is therefore extended. More specifically, the phrasal projection of $\gamma^{0}$, i.e., $\gamma \mathrm{P}$, can be considered to be the extended phase (see Dikken 2007, Gallego 2010 among others, or more flexible phasal definition in Bošković 2014). ${ }^{12}$ In other words, in (17), the $\gamma \mathrm{P}$ is the phase that is the relevant syntactic domain for High tone "agreement" with the verb.

Following Cheng and Downing's (2016) approach in which phases are prosodically mapped to l, the Chimwiini pattern can be accounted for by aligning a High tone to the right edge of every $\varphi$ within the domain of the $\iota$ that maps to the phasal $\gamma \mathrm{P}$. This is comparable to the recent proposal by Sande et al. (2020) that long-distance morphologically conditioned phonological effects are typically bound by phases. The $\iota$ that corresponds to the phasal $\gamma$ P is defined formally by adapting Cheng and Downing's $(2009,2016)$ analysis of prosodic domains in Zulu, sketched above. As shown in (14), above, each phasal domain is right-aligned with $\mathrm{\iota}$. The $\mathrm{CP}$ that defines the root clause is left- and right-aligned with $\mathrm{c}$.

To account for the fact that the phasal $\gamma \mathrm{P}$ alone defines a domain for the final High tone assignment, we need a motivation for also left-aligning an $\mathrm{c}$ boundary with that phasal domain. We observe that Chimwiini shares another property with Zulu, namely, that subjects and other preverbal DPs are phrased separately from what follows. In Zulu, this phrasing is optional for subjects; however, in Chimwiini, it is obligatory, as Kisseberth's (2017) detailed study shows. Note that most Bantu languages are pro-drop languages: a subject marker is obligatorily realized on a main clause verb, but an overt co-referential subject DP is optional. As work since, at least, Bresnan and Mchombo (1987) observes, subject markers therefore ambiguously have both grammatical and anaphoric agreement properties when an overt subject DP occurs. This ambiguity paves the way for subject DPs to be analyzed either as a clause-external topic or as a clause-internal subject. In Chimwiini, we propose, following Cheng and Downing's $(2009,2016)$ analysis of similar phrasing patterns in other Bantu languages, that the subject is actually a clause-external topic, adjoined to the root clause $\mathrm{CP}$ on a separate plane and therefore phrased separately from it, just as other left-dislocated constituents are: ${ }^{13,14}$ 
(18)

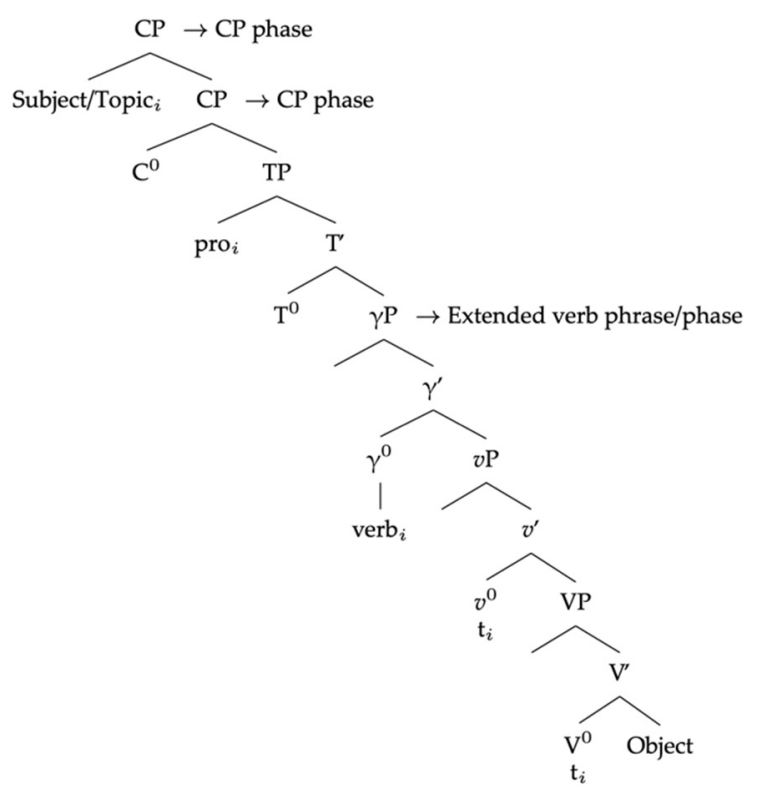

Formally, this phrasing is achieved by left-aligning the phase beginning the root clause with $\mathrm{l}$. The subject/topic is parsed into its own $\mathrm{\iota}$ to satisfy the constraint STRONGSTART (19), which penalizes unparsed or recursively parsed material at the left edge of a prosodic domain (see Selkirk 2011, p. 470 for a similar formal analysis of preposed DPs in XiTsonga).

(19) StrongStart (Selkirk 2011; Figure [38])

A prosodic constituent $(\pi)$ optimally begins with a leftmost daughter constituent that is not lower in the prosodic hierarchy than the constituent that immediately follows:

$*\left(\pi_{\mathrm{n}} \pi_{\mathrm{n}+1} \ldots\right.$

The analysis of the Chimwiini example (16b), which incorporates STRONGSTART into the constraint set motivated for Zulu, is exemplified in the tableau in (20); NORECURSION is omitted from this tableau as it is too low-ranked to determine the optimal output. Note that STRONGSTART must outrank the syntax-prosody correspondence constraints AlignR(Phase) and AlignR(IntPh) in order to optimize a prosodic parse that does not mirror syntactic constituency:

(20) Parse into Intonation Phrase ( $\mathrm{\iota}$; curly brackets indicate $\iota$ boundaries

\begin{tabular}{|c|c|c|c|c|c|}
\hline & [ср (sí) $\left.\left.\left.)_{\varphi}[\text { ср [үР chi-lele (masku mazimá) })_{\varphi}\right]\right]\right]$ & $\begin{array}{c}\text { ALIGNL } \\
(\mathrm{CP})\end{array}$ & $\begin{array}{c}\text { STRONG } \\
\text { START }\end{array}$ & $\begin{array}{c}\text { ALIGNR- } \\
\text { (PHASE) }\end{array}$ & $\begin{array}{c}\text { ALIGNR- } \\
\text { (INTPH) }\end{array}$ \\
\hline a. & $\left\{\left[\mathrm{CP}(\mathrm{si})_{\varphi}\left\{\left[\mathrm{CP}[\gamma \mathrm{P} \text { chi-lele (masku mazimá) })_{\varphi}\right]\right]\right\}\right\}$ & & $*$ *! & & \\
\hline b. & $\left\{\left\{\left[\mathrm{CP}(\text { sí) })_{\varphi}\right\}\left\{\left[\right.\right.\right.\right.$ СР $\left.\left.\left.\left.[\gamma \mathrm{P} \text { chi-lele (masku mazimá })_{\varphi}\right]\right]\right\}\right\}$ & & & & $*$ \\
\hline C. & $\left\{\left[\mathrm{CP}(\mathrm{si})_{\varphi}\left[\mathrm{CP}\left[\gamma_{\mathrm{P}}\right.\right.\right.\right.$ chi-lele $\left.\left.\left.\left.(\text { masku mazimá) })_{\varphi}\right]\right]\right\}\right\}$ & $* !$ & & & \\
\hline
\end{tabular}

As shown, Candidate (20b), which parses the subject DP into both a Phonological Phrase and an Intonation Phrase, is optimal because this parse satisfies STRONGSTART. In this parse, both the first prosodic constituent (within the outermost Intonation Phrase) and the one that follows are Intonation Phrases. As a result, the first prosodic constituent is on the same level of the Prosodic Hierarchy as the second one. This contrasts with (20a), which violates STRONGSTART because the first prosodic daughter of the sentence is a Phonological Phrase, which is lower in the Prosodic Hierarchy than the second prosodic daughter, which is an Intonation Phrase. Candidate (20c) satisfies STRONGSTART: the initial Phonological Phrase is followed by unparsed material, which is necessarily lower in the Prosodic Hierarchy. However, this parse is non-optimal as it violates higher-ranked AlignL (CP).

To sum up, under this analysis, there is no need to appeal to recursive prosodic structure to account for the apparently iterative final High tone assignment in Chimwiini. 
This is a welcome result since there is no recursive syntactic structure to motivate a parse into recursive $\varphi$.

\section{Rethinking $\varphi$ Prosodic Recursion within (Extended) $v \mathbf{P}$}

The Chimwiini example is instructive as it provides our first case study where the recursive Phonological Phrase $(\varphi)$ structure proposed in previous analyses is not motivated by recursive syntactic structure in current syntactic theory. Moreover, we saw that in Chimwiini recursive $\varphi$, at least in the outermost recursion, maps a syntactic category that more closely matches the definition of the Intonation Phrase $(\iota)$, namely, a phasal $\gamma \mathrm{P}$ (the extended verb phrase). In this section, we review other cases like this, providing alternative analyses that avoid syntactically unmotivated prosodic recursion.

\subsection{Kimatuumbi}

Truckenbrodt $(1995,1999)$ influential analysis of prosodic phrasing in Kimatuumbi (Bantu P.13, Tanzania) reanalyzes data discussed in detail in Odden $(1987,1990)$ and proposes that $\varphi$ recursion provides the best way of defining the context of two different syntactically conditioned processes, Shortening and Phrasal Tone Insertion, which have partially overlapping domains. The process of Shortening, as its name implies, shortens underlyingly long vowels in the following syntactic configurations: ${ }^{15}$

(21) Syntactic context for Shortening NP $(N+$ modifier $)$
a. kikóloombe 'cleaning shell'
b. mikaáte
'loaves'
c. lukkaámba
'string'
$V P(V+$ complement $)$
d. naa-kálaangite 'I fried'
e. naa-n-kálaangiile 'I fried for him'

(Odden 1987, p. 17; Truckenbrodt 1995, pp. 105, 106)

\author{
kikólombe chaángu \\ 'my cleaning shell' \\ miksaté mikuúlu misúlú \\ 'large loaves' \\ lukkambá lwalúpuwáaniiké \\ 'string which broke'
}

naa-kálangite chóolyá

'I fried food'

naa-n-kálangile ywaápalá kálaanga

'I fried for the one who wanted to fry'

Shortening does not apply if the words are in distinct XPs; for example, it does not apply to a subject followed by the verb (22a) or to a verb followed by a (focus) adverb (22b), and it also does not apply to the first complement of a verb when followed by a second complement (22c):

(22) Shortening fails to apply
a. kikóloombe 'cleaning shell'
b. aakálaanga 's/he will fry'
c. kikóloombe 'cleaning shell'

(Truckenbrodt 1995, pp. 106, 108) kịkóloombé chaapúwaaniịke 'The cleaning shell is broken.' aakálaanga sáána 'S/he will really fry.' naa-m-pei kikóloombe Mambóondo 'I gave a cleaning shell (to) Mamboondo.'

Truckenbrodt $(1995,1999)$ follows Cowper and Rice (1987) in proposing that the domain for Shortening can be defined by right-aligning Phonological Phrase $(\varphi)$ with lexical XP, adopting Larson (1988) syntax (see discussion of (5) and (6), above):

(23) $\varphi$-construction $\quad$ (Truckenbrodt 1995, p. 107, Figure [48a])

Each right edge of [lexical] XP must coincide with the right edge of a $\varphi$. 
This algorithm correctly places a $\varphi$ edge following every lexical XP (argument), yielding the schematic prosodic phrasings below (adapted from Truckenbrodt 1995, 1999):

(24) a. $\left.\left.\left.\left.\left.\left.\left.\quad \mathrm{S}]_{\mathrm{NP}}\right)_{\varphi} \mathrm{V} \mathrm{O}\right]_{\mathrm{NP}}\right)_{\varphi} \mathrm{O}\right]_{\mathrm{NP}}\right)_{\varphi} \mathrm{Adv}\right]_{\mathrm{ADVP}}\right)_{\varphi}$

b. $\left.\quad \mathrm{N} \mathrm{Adj}]_{\mathrm{NP}}\right)_{\varphi}$

Shortening can then be defined as a process that applies $\varphi$-internally, but not to $\varphi$-final elements.

The second process, Phrasal Tone Insertion (PTI), applies in a partially overlapping domain. This process inserts a High tone on the final syllable of certain constituents of the clause, such as on the subject (22a) and (25e) or a preverbal object or focus adverb ${ }^{16}(25 a, b)$, between a VP and a sentential adverb (25c), and between two clauses (25d):

(25) Contexts for PTI (Truckenbrodt 1995, p. 111; Odden 1987, p. 22); right parentheses highlight occurrences of PTI

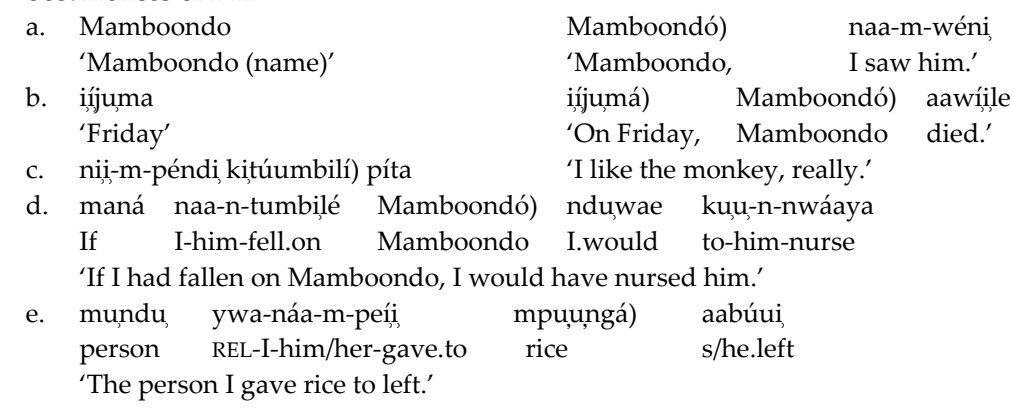

All of these phrase breaks would also be predicted by the $\varphi$-alignment algorithm in (23), since they fall at the right edges of XPs, as Truckenbrodt $(1995,1999)$ defines them. However, as shown in (26), PTI does not apply between verbal complements, as would be predicted if PTI had the same domain as Shortening; notice, too, that PTI never applies to a sentence-final syllable:

(26) No PTI between complements of the verb naa-m-péi lí, Mamboondo kiwikilyo iíjuma I-him-gave NEG Mamboondo cover Friday 'I didn't give Mamboondo a cover on Friday.'

(Truckenbrodt 1995, p. 112)

*....Mamboondó) kịwikilyó) iíjumá)

What is required is a mechanism for grouping the verb and its complements into a single prosodic constituent so that the complements are not all targets of PTI, even though they are targets of Shortening. The same algorithm should also account for the other contexts for PTI illustrated in $(22)$ and $(25)$. Truckenbrodt $(1995,1999)$ proposes that XPs within the verb phrase are parsed into recursive $\varphi^{\prime} s$ in Kimatuumbi, ${ }^{17}$ and that the context for PTI is the left edge of $\varphi$ :

(27) Phrasal Tone Insertion (final version; Truckenbrodt 1995, p. 117, Figure [63]) Align the left edge of every $\varphi$ with the right edge of a High tone.

As we can see in the schematized sentence in (28), this correctly accounts for the context of PTI, if verbal complements are recursively phrased with the verb. PTI correctly only applies between the subject and the verb since that is the only locus of a left edge of $\varphi$ :

(28) $(\mathrm{S})_{\varphi}\left(\left((\mathrm{V} \mathrm{O})_{\varphi} \mathrm{O}\right)_{\varphi} \mathrm{Adv}\right)_{\varphi}$

Although appealing to recursive $\varphi$ provides a technique that allows the verb and its complements to be parsed into a single prosodic constituent, it clearly misses generalizations about PTI that argue in favor of it being a property of the Intonation Phrase ( 1 ) rather than $\varphi$. First, PTI is plausibly interpreted as a tonal version of a continuation rise (Cruttenden 1981): the non-final major constituents of the sentence end in a rising pitch. This is a common intonational phenomenon cross-linguistically, including in other African tone 
languages (see papers in Downing and Rialland 2017), and, as work such as Nespor and Vogel (1986) and Selkirk (2009) argues, the Intonation Phrase is the proper domain for such phenomena. Further, it is striking that elements outside the root clause- such as preverbal objects and adverbs and subordinate or coordinate clauses-provide the context for PTI. As work such as Nespor and Vogel (1986) observes (see, too, Hamlaoui and Szendroï 2015 and Selkirk 2011), these are contexts where, cross-linguistically, one expects an Intonation Phrase break. Note that, as in Chimwiini, subjects and preverbal Topics pattern together, in this case, as contexts for PTI, as well as Shortening. Finally, recall from the analysis of the Chimwiini extended verb phrase in (17), above, that the constituent that contains a verb plus its complements in modern syntactic theory is a phasal XP, not a lexical XP, and phasal domains correspond to $\mathrm{l}$, as argued for at the beginning of Section 2.2.

Truckenbrodt (1995) argues, following Odden (1987), that the context of PTI cannot be $\mathrm{l}$, though, because $\mathrm{t}$ is the context for a process that takes a larger domain, namely, Final Fall, which assigns a Low tone to the right edge of certain clauses. We agree that Final Fall is clearly an intonational process. We propose that its context is complementary to that of PTI: PTI applies to the final syllable of a non-final 1 , while Final Fall applies to the final syllable of the final $\mathrm{t}$ in a clause. Following Ito and Mester (2013) and subsequent work, we label the outermost $\mathrm{l}$, the one that parses the entire sentence, " 1 max".

As schematized in (29), the prosodic analysis of Kimatuumbi thus becomes essentially identical to that sketched for Chimwiini above. Each argument XP is parsed into a $\varphi$, while the verb and its complements are parsed into the 1 that maps the extended verb phrase $(\gamma \mathrm{P})$. Since subjects and preverbal topicalized elements are both targets of PTI, we propose that in Kimatuumbi, as in Chimwiini, subjects are Topics and thus outside the root clause, parsed into an $\iota$ just like the following $\mathrm{CP} / \gamma \mathrm{P}$ to satisfy high-ranked STRONGSTART (see the tableau in (20)). This yields the following reanalysis of the schematized sentence in (28), where curly brackets indicate $\iota$ boundaries and parentheses indicate $\varphi$ boundaries - $\mathrm{cf}$. (20b):

$$
\text { (29) } \left.\left\{\left([\mathrm{S})_{\varphi}\right\}_{\ell}\left\{\left[\mathrm{V}(\mathrm{O})_{\varphi}(\mathrm{O})_{\varphi}(\mathrm{Adv})_{\varphi}\right]_{\gamma \mathrm{P}}\right\}_{\ell}\right]_{C \mathrm{P}}\right\}_{\ell-\max } .
$$

As in Truckenbrodt's $(1995,1999)$ analysis, the domain of Shortening is $\varphi$ : the process applies to words that are non-final in $\varphi$. The domain of PTI is $\mathrm{i}$ : a High tone (or continuation rise) occurs at the right edge of every non-final $\mathrm{l}$ (that is, it is a domain juncture process). The domain of Final Fall is $1_{\max }$. Note that recursion of $t$ in (29) mirrors phasal domain recursion of the extended verb phrase $(\gamma \mathrm{P})$ and $\mathrm{CP}$.

Recursion of $\varphi$ does not play a role in the analysis, however. As a result, it avoids several issues raised by Truckenbrodt's $(1995,1999)$ analysis. First, the outermost recursion of $\varphi$ in Truckenbrodt's analysis does not parse a lexical XP in modern syntactic theory, contrary to the standard definition of this prosodic category. Rather, it maps to a phasal $\gamma \mathrm{P}$ (the extended verb phrase). Furthermore, prosodic recursion in his analysis does not mirror syntactic recursion in modern syntactic theory, for the reasons discussed above for Chimwiini. Nor does it meet the definition of phonological recursion: each instance of $\varphi$ should define the context for the same phonological processes, yet only some $\varphi$ 's trigger PTI. ${ }^{18}$ Finally, the recursive $\varphi$ analysis misses cross-linguistic generalizations by proposing that $\varphi$, not 1 , is the domain of the intonational process of PTI (continuation rise).

In spite of these issues, recursive $\varphi$, rather than 1 , continues to be appealed to in the recent phonological literature to parse phasal categories. We review two recent cases in the next sections and show that they are best reanalyzed in terms of the approach developed in the discussion so far, where prosodic recursion must mirror syntactic recursion.

\subsection{Bàsàá}

Hamlaoui and Makasso (2019) discuss three different prosodic processes in Bàsàa (Bantu A.43a, Cameroon) and propose that they apply in three different prosodic domains, $\varphi_{\min }, \varphi_{\max }$, and $\mathrm{l}$. We briefly present each of the three processes and argue that $\varphi_{\max }$ 
which defines a verb plus its complements as a prosodic domain-is better reanalyzed as I.

We begin with the process of High Tone Spread (HTS), which turns input H-L and $\mathrm{H}-\varnothing$ tonal sequences into $\mathrm{H}-\mathrm{HL}$ and $\mathrm{H}-\mathrm{H}$ sequences, respectively. As Hamlaoui et al. (2014) argue, HTS takes $\varphi$ as its domain. Indeed, it applies in the same contexts as defined for the final High tone assignment in Chimwiini or for Shortening in Kimatuumbi: between a verb and a following complement, but not between two verbal complements and not between the subject and verb:

(30) $\left.\left.\left.\left.\left.S]_{N P}\right)_{\varphi} \mathrm{V} \mathrm{O}\right]_{N P}\right)_{\varphi} \mathrm{XP}\right]_{N P}\right)_{\varphi}$

That is, this domain is straightforwardly defined by right-aligning $\varphi$ to DP/NP (XP arguments). Certain nominal modifiers introduce complications that we do not discuss here, for ease of cross-linguistic comparison.

The process of Final Tone Simplification (FTS) turns input HL-H tonal sequences into H-!H, where !H indicates a downstepped High tone. Hamlaoui and Szendroï (2015) argue that the domain for FTS is $\iota$, as it applies between all of the lexical XPs that are contained within the same (root) clause. For example, it applies between the subject and verb, or between a verb and a following adjunct, or between verbal complements. However, it does not apply between a left-dislocated constituent (i.e., a Topic) and the remainder of the sentence. The definition of $\iota$, like the definition of $\varphi$, is thus consistent with the usual syntactic definitions of these prosodic constituents (see (9), above): ı correlates with root $\mathrm{CP}$ or a phase and $\varphi$ correlates with an XP argument.

Hamlaoui and Makasso (2019) present a third tonal process, Downstep, which turns input $\mathrm{H}-\mathrm{H}$ tonal sequences into $\mathrm{H}-$ !H. This process applies only between two complements of a verb or between a verbal complement and a verbal modifier. That is, it applies within a domain intermediate in size between $\varphi$ and $\iota$, and the question arises of how to define this domain syntactically and which prosodic category it correlates with. Hamlaoui and Makasso (H\&M) follow Truckenbrodt's $(1995,1999)$ analysis of Kimatuumbi, adopting Larson's (1988) VP structure and parsing the verb and its complements into a single prosodic constituent using recursive $\varphi$ (but distinguishing $\varphi$ from $\varphi_{\max }$ ):

(31) $\left((\mathrm{V} X \mathrm{P})_{\varphi} \mathrm{XP}\right)_{\varphi-\max }$

However, as we have argued above, this parse is problematic. The outermost $\varphi$ (i.e., $\left.\varphi_{\max }\right)$ does not parse a lexical XP in current syntactic theory (but rather a phasal $v \mathrm{P}$ ), contrary to the standard definition of this prosodic constituent. We adapt H\&M's analysis of double object sentences, with the higher VP changed to vP. Further, we follow H\&M in assuming that the verb moves to the higher verb (i.e., little $v),{ }^{19}$ and the $v \mathrm{P}$ projection is a phase; it is best mapped to the prosodic phrase ı. It should be noted that under H\&M analysis, prosodic recursion does not mirror syntactic recursion in current syntactic theory, for the reasons discussed above when analyzing Chimwiini. Nor does it meet the definition of phonological recursion: each instance of $\varphi$ should be the context for the same phonological processes, yet H\&M show that only the $\varphi_{\max }$ that maps to the phasal $v \mathrm{P}$ domain provides the domain for Downstep, and Downstep only occurs at the juncture between two verbal complements. In short, prosodic recursion is used in their analysis as a technical device to parse the verb and its complements into a prosodic constituent in a way that is not consistent either with current syntactic theory or the usual linguistic definition of recursion.

We propose that $\varphi_{\max }$ is best reanalyzed as $\iota$, while H\&M's $\iota$ is best reanalyzed as $\iota_{\max }$. For one thing, this use of prosodic recursion is justified by the syntax. Recall from Section 2.1 that $v \mathrm{P}$ and $\mathrm{CP}$ define phasal recursions that are expected to be mirrored by prosodic recursion. The distinction between $\iota$ and $\iota_{\max }$ is justified by the generalization that there is often a distinction between the prosody found in the $\iota_{\max }$ that maps a root clause and the prosody found in an $\iota$ that is mapped to a root clause-internal phasal domain. For example, in Kimatuumbi, recall that PTI applies to the final syllable of $\iota$, that is, to CP-internal $\iota$, whereas Final Fall applies to the $\iota_{\max }$ that parses the entire sentence (see (29), 
above). This analysis motivates the following prosodic parse of the domains for FTS and Downstep:

(32) $\left\{\left\{[\text { Topic }\}\left\{\left[(\mathrm{S})_{\varphi}\left\{\left[\mathrm{V}(\mathrm{O})_{\varphi}(\mathrm{O})_{\varphi}\right]_{v P}\right\}_{\iota}\right]_{C P}\right\}_{\iota}\right]_{C P}\right\}_{\iota-m a x}$

We leave the formal analysis to the reader, as it so closely follows the analyses provided above for Chimwiini and Kimatuumbi.

\subsection{Akan}

A final case that we will discuss where recursive $\varphi$ is used as a device to parse a verb plus its complements into a single prosodic constituent is Kügler's $(2015,2017)$ analysis of prosodic domains in Akan (Kwa, Ghana). As Kügler shows, a process of Regressive Vowel Harmony (RVH) applies not only within words, but also across certain word boundaries. It applies between a verb and a following object and also between an object and a following second object or adverb, but not between the subject and a following verb. However, it does apply between words within NP.

These contexts should by now be familiar from the languages discussed up to this point, and Kügler gives them the familiar analysis à la Truckenbrodt $(1995,1999) . \varphi$ is mapped to lexical XPs, and complements of a verb are mapped to a recursive $\varphi$ that includes the verb:

(33) $\left.\left.\left.\left.(\mathrm{S}]_{\mathrm{NP}}\right)_{\varphi-\max }\left(\left((\mathrm{V} \mathrm{O}]_{\mathrm{NP}}\right)_{\varphi} \mathrm{O}\right]_{\mathrm{NP}}\right)_{\varphi} \mathrm{Adv}\right]_{\mathrm{ADVP}}\right)_{\varphi-\max }$

RVH can thus be defined as applying within words and across word boundaries within $\varphi_{\max }$.

The usual critique for parsing the verb and its complements into recursive $\varphi$ continues to apply to this example. The outermost recursion of $\varphi$ does not parse a lexical XP, contrary to the standard definition of this prosodic constituent. Rather, it maps to a phasal XP (e.g., $v \mathrm{P}$ or $\mathrm{CP}$ ) domain in modern syntactic theory. ${ }^{20}$ Furthermore, prosodic recursion in this analysis does not mirror syntactic recursion in a minimalist analysis, for the reasons discussed above. Finally, it is not clear why a subject NP should be parsed into $\varphi_{\max }$, while verbal complement NPs are parsed as $\varphi$. All NPs should, all things being equal, be given the same prosodic parse.

In contrast, as we have shown, parsing the verb and its complements-a phasal $v \mathrm{P}$ in modern syntactic theory-into an $\iota$ avoids these conceptual problems. The alternative parse provided by our approach, given in (34) below, cf. (32), allows the context for RVH to be restated simply as applying regressively within and across $\varphi$ boundaries but not across $\mathrm{l}$, as expected, since $\mathrm{\imath}$ is a strong prosodic boundary. The prosodic phrasing for Akan, given below, is essentially identical to that proposed for Bàsàá in (32) above:

(34) $\left\{\left[(\mathrm{S})_{\varphi}\left\{\left[\mathrm{V}(\mathrm{O})_{\varphi}(\mathrm{O})_{\varphi}(\mathrm{Adv})_{\varphi}\right]_{v \mathrm{P}}\right\}_{l}\right]_{C \mathrm{P}}\right\}_{1-\max }$

To sum up this section, we have shown that the syntactic constituent that contains a verb and two complements is phasal $v \mathrm{P}$. Phasal $v \mathrm{P}$ is parsed into $\mathrm{l}$, as this is the prosodic constituent which, by definition, corresponds to a phasal syntactic domain (see discussion of (9), above). This proposal allows us to provide a similar prosodic parse for similar syntactic structures in Akan, Chimwiini, Kimatuumbi, and Bàsàá ${ }^{21}$, and it allows the prosodic structure to more closely mirror syntactic structure, since prosodic recursion is only found when motivated by syntactic recursion, to satisfy syntax-prosody mapping constraints. It thus better satisfies the principles of the Syntax-Prosody Mapping Hypothesis (SPMH) in (1), above, which require all prosodic categories to be grounded in syntactic categories, with the default universal prosody-syntax correspondences defined in (9) and discussion following (9). By strictly following the principles of the SPMH, the proposal satisfies the requirement that specific syntactic domains will map, cross-linguistically, to the same prosodic domains, unless prosodic well-formedness principles interfere with this default mapping. 


\section{Rethinking $\varphi$ Prosodic Recursion at the Clause Level}

So far, we have discussed cases where the use of recursive $\varphi$ to parse a verb and its complements was motivated by the Larsonian (Larson 1988) VP shell, which, as we argued, must be rethought in the light of developments since 1995 in syntactic theory. Surprisingly, in some recent analyses, such as Elfner (2015) and Elordieta (2015), recursive $\varphi$ has even been used to parse an entire root clausal domain, thus abandoning a traditional distinction between the types of syntactic constituents that the Phonological Phrase vs. the Intonation Phrase correspond to (see (9), above). In so doing, they also abandon fundamental principles of the SPMH (1), namely, that "the principles governing the syntaxprosody mapping are universal in nature" (Bennett and Elfner 2019, p. 158) and that "the fundamental syntactic distinctions between clause, phrase and word should be reflected in, and retrieved from, the phonological representation" (Selkirk 2011, p. 440; see (1b)). In more formal terms, these analyses violate the universal constraints (see (9), above) optimizing a match (or mutual alignment) between the Intonation Phrase and Clause/phase, unless higher-ranked prosodic constraints motivate misalignment. In this section, we critique this use of recursive $\varphi$ in Elfner's (2015) analysis of Connemara Elordieta's (2015) analysis of Basque.

\subsection{Recursive $\varphi$ in Connemara Irish}

Elfner (2015) provides a detailed discussion of the distribution of two phrase accents in Connemara Irish, LH and HL. The distribution of LH and HL is illustrated in the VSO sentence in (36), below, where the subject and object DPs consist of a noun followed by an adjective. As we can see, HL is found at the right edge of every DP. LH is found at the beginning of the clause ( $\Sigma \mathrm{P}$ in the syntactic analysis that Elfner adopts) and at the beginning of TP in a VSO sentence like the one in (35), represented in $(36 a, b)$ :

\begin{tabular}{|c|c|c|c|}
\hline $\begin{array}{l}\text { (35) díolfaidh } \\
\text { sell.FUT }\end{array}$ & $\begin{array}{l}\text { leabharlannaí } \\
\text { librarian }\end{array}$ & $\begin{array}{l}\text { dathúil } \\
\text { handsome }\end{array}$ & $\begin{array}{l}\text { blathanna } \\
\text { flowers }\end{array}$ \\
\hline
\end{tabular}

'A handsome librarian will sell beautiful flowers.'

(36) Recursive $\varphi$ mapping in Connemara Irish (VSO sentences) (Elfner 2015, p. 1178)

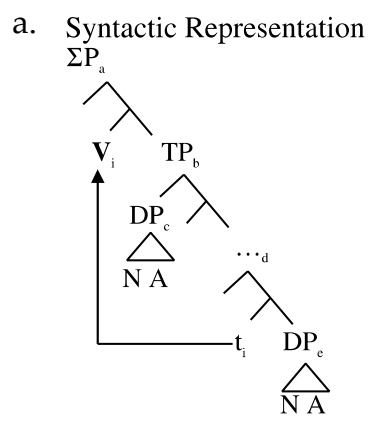

b.

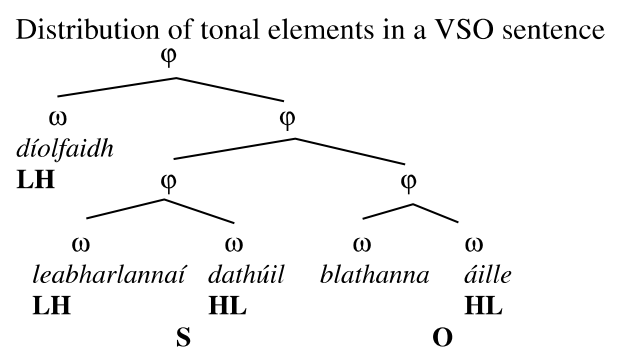

The corresponding prosodic category defining the domain of HL realization is straightforwardly $\varphi$, the same domain, defined in a similar way, as was relevant for the final High tone assignment in Chimwiini, Shortening in Kimatuumbi, and HTS in Bàsàá. Applying the principles of the SPMH, ı appears to be a good candidate for the category defining the domain of LH. It is anchored to a larger syntactic domain than an XP argument and the prosodic domain contains $\varphi$ in the sense that every $\varphi$ ends with an HL melody, but not every $\varphi$ begins with an LH melody. As we can see in (36b), though, Elfner (2015) proposes that $\Sigma \mathrm{P}$ and TP are parsed into recursive $\varphi$ 's. To better understand her motivation for the parse, we need to look at additional data.

As Elfner shows, all of the prosodic phrases that are initiated with LH must satisfy a binary minimality requirement. To illustrate, even though the subject and object are prosodified together in a V S O sentence like the one in (36), they are not phrased together 
in a V S DO IO sentence, as shown in (37). Note the LH at the beginning of the prosodic domain containing both objects:

(37) Recursive phrasing in a V S DO IO sentence (Elfner 2015, p. 1184)

a. díolfaidh rúnaí dathúil blathanna áille le daoine anamúla sell.FUT secretary handsome flowers beautiful.PL with people animated.PL

'A handsome secretary will sell beautiful flowers to animated people.'

b. Syntactic Representation

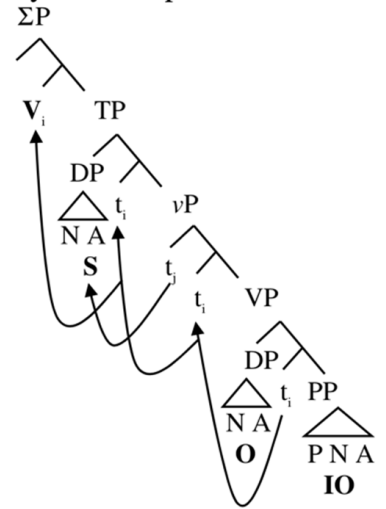

c. Recursive Prosodic Representation

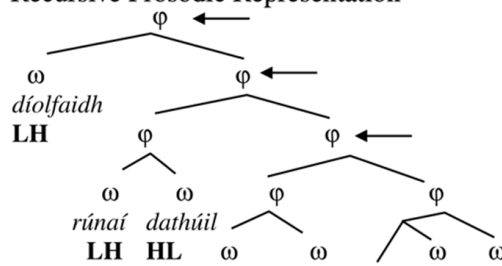

LH H

$\mathbf{S}$ blathanna áille le daoine anamúla

LH

o

IO

Comparing (36) and (37), we can see that if there were an LH between the $\mathrm{S}$ and $\mathrm{O}$ in (36), then LH would occur at the left edge of a constituent parsed into a single $\varphi$, the one parsing O. This is apparently non-optimal. Notice that in (36) and (37), each LH domain dominates at least two $\varphi^{\prime}$ s. Parsing $\mathrm{S}$ and $\mathrm{O}$ together into a larger prosodic constituent, as in (36), allows the prosodic constituent that defines the domain for LH to contain two $\varphi^{\prime}$ s, a common type of binary minimality requirement (Ghini 1993; Inkelas and Zec 1995; Prieto 2005; Selkirk 2011).

The importance of binary minimality in defining the optimal parse of prosodic domains in Connemara Irish is confirmed by an additional example. Even though the $\mathrm{V}$ is prosodified outside the prosodic domain of the subject in a V S O sentence like the one in (36), it is prosodified with the subject in a V S O sentence where the subject does not branch (because the subject noun phrase is not modified by an adjective), as shown in (39b). As Elfner (2015) observes, the prosodic analysis in (39b) suggests that $\varphi$ is subject to a binary minimality condition, formalized in (38):

(38) BINARY-Minimum $(\varphi)$ : a $\varphi$ constituent in the prosodic representation must dominate a minimum of two PWords.

This constraint favors a parse where $\mathrm{V}$ and $\mathrm{S}$ (each consisting of a single PWord) are contained in the same $\varphi$. As noted above, the domain for LH must contain at least two $\varphi$, a requirement that is also satisfied in (39b):

(39) Recursive phrasing in a V S O sentence with non-branching S a. $\Sigma \mathrm{P}[$ Cheannaigh $\mathrm{TP}[\mathrm{DP}[$ múinteoirí $] \quad \mathrm{VP}[\mathrm{DP}[$ bought teachers bags white.PL

'Teachers bought white bags.'

b. Proposed prosodic representation for VSO with non-branching subject (= Elfner's [42])

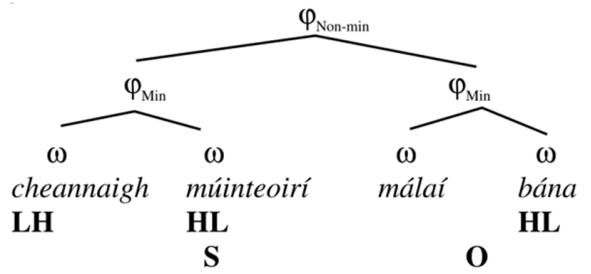

The generalization that emerges from the data is that LH only occurs at the left edge of a domain that contains minimally two $\varphi$ 's. 
To account for this generalization, Elfner (2015, p. 1170) proposes that the LH accent "appears only in the presence of recursive prosodic structure". This is the structure shown in the representations above. However, there are reasons to be skeptical of this use of prosodic recursion. First, binarity minimality requirements usually evaluate two different levels of the prosodic hierarchy. For example, a PWord binary minimality or maximality requirement is satisfied (or not) depending on how many syllables or moras it parses (McCarthy and Prince 1986). Binary minimality or maximality for $\varphi$ is satisfied depending on how many PWords it parses (Elfner 2015; Ghini 1993; Inkelas and Zec 1995; Prieto 2005; Selkirk 2000, 2011). Thus, if LH initiates a prosodic structure that must include at least two $\varphi^{\prime}$ s, the appropriate prosodic category parsing the domain is the one that dominates $\varphi$, namely, $\mathrm{t}$.

Second, one also finds the problems identified in the preceding discussions with the use of prosodic $\varphi$ recursion in Elfner's analysis. The outermost recursion is anchored to a root clause, not a lexical XP. This parse also means that Connemara Irish does not have both $\varphi$ and $\iota$, thus violating a central principle of the SPMH (1). In addition, there is clear evidence that the XP argument-anchored prosodic domains are associated with different prosodic correlates than the domains that parse phasal structures. Each XP argumentanchored $\varphi$ domain is followed by HL, while the larger domains, which must contain at least two $\varphi^{\prime}$ s, are associated with initial LH. As a result, recursive $\varphi$ domains are not associated with the same prosody, which many consider problematic, as noted above.

We propose, then, that $\varphi_{\text {non-min }}$ in Elfner's analysis be reanalyzed as ı. Following Cheng and Downing (2016), the left edge of a phase, CP or $v$ P maps asymmetrically to เ. However, as we have seen, $\mathrm{l}$, like $\varphi$, is subject to a binary minimality constraint in Connemara Irish, formalized in (40), leading to mismatches between prosodic categories and the syntactic ones they are anchored to.

(40) BINARY-MinimUM( $\iota$ : an $\iota$ constituent in the prosodic representation must dominate a minimum of two $\varphi^{\prime}$ s.

The interaction of syntactically anchored prosodic alignment and prosodic constraints yields the following parses of the structures in (36), (37), and (39), adopting the definitions of $\iota$ and $\varphi$ discussed for (9) above:

(41) a. V S O, branching subject and object - cf. (36)

$$
\begin{aligned}
& \left.\left\{\left[\begin{array}{lllll}
\Sigma \mathrm{P} & \mathrm{V} & \left\{\left(\left[\begin{array}{lll}
\mathrm{N} & \mathrm{A}
\end{array}\right]\right)_{\varphi}\right. & \left(\left[\begin{array}{lll}
\mathrm{vP} & \mathrm{N} & \mathrm{A}
\end{array}\right]\right)_{\varphi} & ]
\end{array}\right\}_{\mathrm{L}}\right]\right\}_{\mathrm{r}} \\
& \text { LH LH HL HL }
\end{aligned}
$$

b. V S O, non-branching subject, branching object - cf. (39)

$$
\begin{aligned}
& \left\{\left[\begin{array}{lllll}
\Sigma \mathrm{PP} & \mathrm{V} & [\mathrm{N}]) \varphi & \left(\left[\begin{array}{lll}
\mathrm{vP}[ & \mathrm{N} & \mathrm{A}
\end{array}\right]\right) \varphi & ]\}_{\llcorner}
\end{array}\right]\right\}_{\mathrm{r}} \\
& \text { LH HL } \\
& \text { HL } \\
& \text { c. V S DO IO - cf. (37) }
\end{aligned}
$$

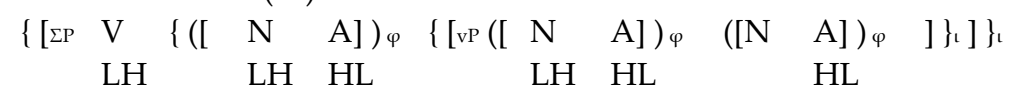

Note that, in the majority of the cases in (41), $\iota$ is left-aligned with $\varphi$. However, as we

\begin{tabular}{|c|c|c|c|c|c|c|}
\hline (42) & V S O, branching subject and object & - cf. (36) & & & & \\
\hline & {$[\Sigma \mathrm{P} V[\mathrm{~N} \mathrm{~A}][v \mathrm{p}[\mathrm{N} \mathrm{A}]]]$} & BINMIN(I) & $\operatorname{BINMIN}(\Phi)$ & $\begin{array}{c}\text { STRONG } \\
\text { START }\end{array}$ & $\begin{array}{c}\text { AliGnL } \\
\text { (PHASE, I) }\end{array}$ & $\begin{array}{c}\text { AliGNL } \\
(\Phi, X P)\end{array}$ \\
\hline a. & $\left\{\left[\Sigma \mathrm{P} \mathrm{V}\left\{([\mathrm{N} \mathrm{A}])_{\varphi}\left(\left[{ }_{v \mathrm{P}}[\mathrm{N} \mathrm{A}]\right)_{\varphi}\right]\right\}_{\llcorner}\right]\right\}_{\mathrm{L}}$ & & & * & $*$ & \\
\hline b. & 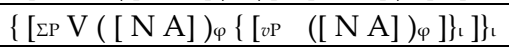 & $*$ & & $* *$ & & \\
\hline c. & $\left.\left(\left[\Sigma \mathrm{P} V([\mathrm{~N} \mathrm{~A}])_{\varphi}\left([v \mathrm{P}([\mathrm{N} \mathrm{A}]])_{\varphi}\right]\right)_{\varphi}\right]\right)_{\varphi}$ & & & * & $* * !$ & ** \\
\hline
\end{tabular}
see in (41a) and (41c), it is often optimal in Connemara Irish for the V to be parsed outside of the initial $\varphi$, in violation of STRONGSTART (19), since V is only parsed with a following DP to satisfy $\varphi$ minimality (see $(41 b)$ ).

The formal analysis of each of these sentence types is exemplified in the tableaux in (42)-(44). We begin with the analysis of sentence type (41a): 
In (42), the purely syntactically motivated prosodic parse in (42b) is non-optimal, as it would violate the binary minimality requirement for the inner $\iota$, the one left-aligned with $v \mathrm{P}$ in this parse. Candidate (42a) is optimal, as it satisfies both high-ranked prosodic minimality constraints while violating a lower-ranked syntactic alignment constraint. Candidate (42c), the parse proposed in Elfner (2015) — cf. (36), above-is non-optimal, as neither of the phasal constituents is parsed into an Intonation Phrase, even though no higher-ranked constraint motivates this mismatch. Instead, the phasal constituents are parsed into Phonological Phrases in (36), violating $\operatorname{AligNL}(\varphi, \mathrm{XP})$. All candidates in this tableau violate STRONGSTART since in all candidates, the outermost Intonation Phrase starts with material - the verb-which is unparsed into a prosodic constituent. Unparsed starting material is necessarily lower ranked in the Prosodic Hierarchy than a following Phonological Phrase (42b, c) or Intonation Phrase (42a).

The analysis of sentence type (41b) is exemplified in (43):

(43) V S O, non-branching subject, branching object - cf. (39)

\begin{tabular}{|c|c|c|c|c|c|}
\hline & {$[\Sigma \mathrm{P} V[\mathrm{~N}][v \mathrm{P}[\mathrm{N} \mathrm{A}]]]$} & BINMIN(I) & $\operatorname{BINMIN}(\Phi)$ & $\begin{array}{c}\text { STRONG } \\
\text { START } \\
\end{array}$ & $\begin{array}{c}\text { AlignL } \\
\text { (PhASE, I) } \\
\end{array}$ \\
\hline a. & $\left\{\left[\Sigma \mathrm{P}(\mathrm{V}[\mathrm{N}])_{\varphi}([v \mathrm{P}[\mathrm{N} \mathrm{A}]) \varphi]\right]\right\}_{\mathrm{L}}$ & & & & * \\
\hline b. & 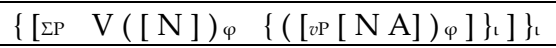 & *! & $*$ & * & \\
\hline c. & $\left\{\left[\Sigma \mathrm{P} \quad(\mathrm{V} \quad[\mathrm{N}]) \varphi\{([v \mathrm{P}[\mathrm{N} \mathrm{A}]) \varphi]\}_{\mathrm{L}}\right]\right\}_{\mathrm{L}}$ & *! & & * & \\
\hline $\mathrm{d}$. & $\left(\left([\Sigma \mathrm{P} \mathrm{V}[\mathrm{N}])_{\varphi}\left([v \mathrm{P}[\mathrm{N} \mathrm{A}])_{\varphi}\right]\right]\right)_{\varphi}$ & & & & $* * !$ \\
\hline
\end{tabular}

The role of binarity at the level of both $\varphi$ and $\iota$ is illustrated in (43). The subject and verb are not separated by either a $\varphi$ boundary or an $\iota$ boundary in this case, even though this would satisfy the syntactically motivated alignment constraints. Rather they are parsed into a single $\varphi$ to satisfy $\operatorname{BINMIN}(\varphi)$. This has the added advantage of satisfying minimality at the $\iota$ level $(\operatorname{BINMIN}(\iota))$, as well as STRONGSTART (all of the material parsed by the outermost Intonation Phrase is exhaustively parsed into successive Phonological Phrases, which are equal in the Prosodic Hierarchy). Candidate (43d), the parse proposed in Elfner (2015) — cf. (39), above-is non-optimal, as neither of the phasal constituents is parsed into an Intonation Phrase, even though BINMIN( $\iota$ ) only motivates one mismatch. In addition, the phasal constituents are parsed into Phonological Phrases in (39), violating $\operatorname{AlignL}(\varphi, \mathrm{XP})$.

The analysis of sentence type (41c) is exemplified in (44):

(44) V S DO IO - cf. (37); only crucial constraints included for ease of exposition

\begin{tabular}{|c|c|c|c|c|c|c|}
\hline & {$[\Sigma \mathrm{P} V[\mathrm{~N} \mathrm{~A}] \quad[v \mathrm{P}([\mathrm{N} \mathrm{A}][\mathrm{N} \mathrm{A}]]]$} & $\begin{array}{c}\text { BIN } \\
\text { MIN(I) }\end{array}$ & $\begin{array}{c}\text { BIN } \\
\operatorname{MIN}(\Phi)\end{array}$ & $\begin{array}{c}\text { STRONG } \\
\text { START }\end{array}$ & $\begin{array}{c}\text { AliGnL } \\
\text { (PHASE, I) }\end{array}$ & $\begin{array}{c}\text { ALIGNL } \\
\text { (I,PHASE) }\end{array}$ \\
\hline Fa. & 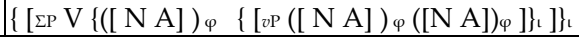 & & & * & & * \\
\hline b. & $\left\{\left[\Sigma \mathrm{PV}([\mathrm{N} \mathrm{A}])_{\varphi}\left\{\left[\mathrm{vP}([\mathrm{N} \mathrm{A}])_{\varphi}([\mathrm{N} \mathrm{A}])_{\varphi}\right]\right\}_{\mathrm{r}}\right]\right\}_{\mathrm{l}}$ & & & $* * !$ & & \\
\hline c. & 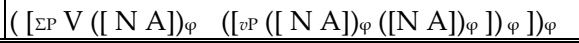 & & & $*$ & $* !^{*}$ & \\
\hline
\end{tabular}

The tableau in (44) shows how the constraint STRONGSTART can play a role in deciding the winning candidate. The optimal candidate in (44a) has one more $\iota$ than expected based on a purely syntactically motivated Phase- $\iota$ mapping: the pre-subject $\iota$ boundary is not motivated by the syntactic structure, as the subject is not preceded by a phase edge. As shown, STRONGSTART (19) can account for this mismatch. The non-optimal parse in (44b) violates this constraint twice, as the outermost $\iota$ begins with an unparsed $V$ followed by a $\varphi$ followed by an $\mathrm{\iota}$. That is, each of the first two daughters of the outermost $\iota$ are lower in the Prosodic Hierarchy than the constituent that follows it. The optimal parse in (44a) better satisfies STRONGSTART by reducing the number of prosodically weak elements at the start of the outermost $\iota$ while also improving the left alignment between the $\varphi$ containing the subject and an I. Candidate (44c), the parse proposed in Elfner (2015) - cf. (37), above-incurs the same number of STRONGSTART violations as (44a). However, it is non-optimal, as neither of the phasal constituents is parsed into an Intonation Phrase, even though no higher-ranked constraint motivates this mismatch. ${ }^{22}$ 
To sum up, an analysis in which recursions of $\varphi$ that map to phasal domains are instead mapped to $\iota$ yields a prosodic parse that better satisfies the core principles of the SPMH in (1). Prosodic categories are mapped to the canonical corresponding syntactic categories defined in (9) unless well-motivated prosodic principles such as binary minimality and STRONGSTART interfere with the syntactically anchored mapping. ${ }^{23}$ As a result, prosodic recursion mirrors syntactic recursion in this re-analysis, and the core distinction between phrase and clause is represented in the output of the prosodic grammar.

\subsection{Recursive $\varphi$ in Basque}

Elordieta (2015) develops an analysis of the distribution of downstep and upstep/partial reset within $v \mathrm{P}$ in Northern Biscayan Basque, a tonal accent language spoken in Spain. The four patterns to be accounted for are illustrated in (45), where a downward arrow $(\downarrow)$ represents downstep and an upward arrow $(\uparrow)$ represents upstep/partial reset:

(45) Basque patterns to be accounted for (Elordieta 2015, p. 53)

a. $\quad$ Type A: $\quad\left[\left[[[N \downarrow N][\downarrow N]]_{\mathrm{DP}}[\downarrow \mathrm{V}]_{\mathrm{VP}}\right]_{\mathrm{vP}}\right]_{\mathrm{TP}}$

$\begin{array}{lclcl}{[[[[\text { Mirénen }} & \downarrow \text { lagúnen }] & {[\downarrow \text { liburúak]]DP }} & {[\downarrow \text { gustaten }} & \left.\left.\mathrm{dxáraz}]_{\mathrm{VP}}\right] v \mathrm{P}\right] \mathrm{TP} \\ \text { Miren-GEN.SG } & \text { friend-GEN.PL } & \text { v book-ABS.PL } & \text { like } & \text { AUX }\end{array}$

'I like Miren's friends' books.'

b. $\quad$ Type B: $\quad\left[\left[[[N \downarrow N][\uparrow N \downarrow A]]_{D P}[\downarrow V]_{v P}\right]_{v P}\right]_{T P}$

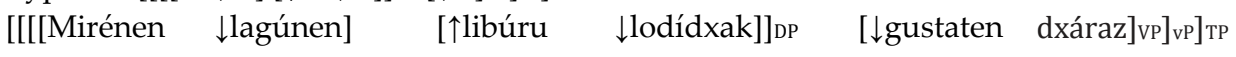
Miren-GEN.SG friend-GEN.PL book thick-ABS.PL like AUX

'I like Miren's friends' thick books.'

c. $\quad$ Type C: $\left[[\mathrm{N} \downarrow N]_{\mathrm{DP}}\left[[\uparrow \mathrm{N}]_{\mathrm{DP}}[\downarrow \mathrm{V}]_{\mathrm{VP}}\right]_{\mathrm{VP}}\right]_{\mathrm{TP}}$

[[[Mirénen $\quad \downarrow$ amúmari $\left.\left.]_{\mathrm{DP}} \quad[\uparrow l \text { liburúak }]_{\mathrm{DP}} \quad\left[\downarrow^{\mathrm{emon}} \text { dótzez }\right]_{\mathrm{VP}}\right]_{\mathrm{VP}}\right]_{\mathrm{TP}}$

Miren-GEN.SG grandmother-DAT.SG book-ABS.PL give AUX

'They have given the books to Miren's grandmother.

d. $\quad$ Type $D: \quad\left[[N \downarrow N]_{D P}\left[[\uparrow \uparrow N \downarrow A]_{D P}[\downarrow V]_{V P}\right]_{V P}\right]_{T P}$

[[[Mirénen \amúmari]DP $\quad\left[\uparrow \uparrow \text { libúru } \downarrow \text { lodídxak]DP } \quad\left[\downarrow \text { emon dótzez] }{ }_{\mathrm{VP}}\right]_{v \mathrm{P}}\right]_{\mathrm{TP}}$

Miren-GEN.SG grandmother-DAT.SG book thick-ABS.PL give AUX

'They have given the thick books to Miren's grandmother.'

Elordieta (2015, p. 53, Figure [3]) observes that the data in (45) illustrate the following generalizations concerning the distribution of downstep and upstep/partial reset:

(46) a. Within a DP, downstep applies to any accented word following another accented word, except in the cases described in (b).

b. When the head noun is followed by a modifier, it shows pitch reset, not downstep (cf. type B).

c. Pitch reset is also observed at the left edge of a verbal projection when it contains a DP preceding the $\mathrm{V}$ (cf. types $\mathrm{C}, \mathrm{D}$ ).

d. Types $B$ and $C$ present a similar degree of pitch reset. However, a higher degree of pitch reset is observed in type D, that is, at the left edge of a two-word DP which is at the left edge of a verbal projection.

The principles of the SPMH in (1) and (9) suggest the following prosodic algorithm to account for these generalizations. Each XP argument is mapped to $\varphi .{ }^{24}$ The domain for downstep and partial reset would be $\iota$. This is not only the prosodic category that is mapped to phasal domains, such as $v \mathrm{P}$ and $\mathrm{CP}$, but it is also the most plausible prosodic domain for intonational phenomena such as downstep and partial reset (see also discussion in Section 3 on Kimatuumbi and Bàsàá). We follow Elordieta (2015, p. 61) and the work cited therein in assuming that (i) the verb in Basque remains in situ, and the auxiliary merges with the verb post-syntactically as a prosodic clitic, parsed as a PWord with the verb; and (ii) determiners and case makers in Basque are morphologically and prosodically 
affixes on the word that precedes them within the DP. In other words, the terminal D node would be empty in prosodic structure, and therefore, in the case of Mirén-en in (47b), it cannot be mapped as an independent $\varphi$ (see Elordieta 2015, p. 61 for more discussion). Our analysis yields the prosodic parses in (47)-(50), where parentheses indicate $\varphi$ and curly brackets indicate $\iota$ (with the morpho-prosodic affixes indicated by dotted lines):

(47) Type A: [[[[N $\left.\left.\downarrow N][\downarrow N]]_{D P}[\downarrow V]_{v P}\right]_{\mathrm{vP}}\right] \mathrm{TP}$
a. $\{$ ( [[[ Mirénen] $]$ lagúnen $])$
Miren-GEN.SG friend-GEN.PL
$\downarrow$ liburúak] )D
$\downarrow$ [gustaten
dxáraz]Vv] $\left.\left.\left.{ }_{\mathrm{VP}}\right\}\right]_{\mathrm{TP}}\right\}$
like AUX

'I like Miren's friends' books.

b.

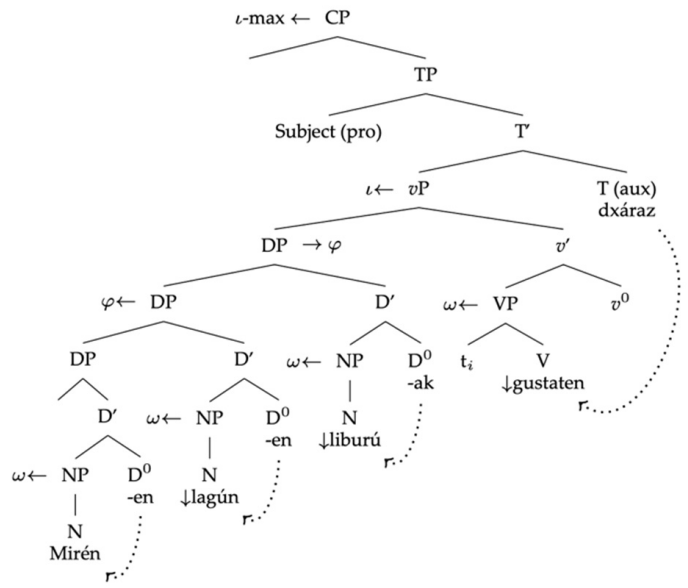

As we can see in (47), there are four PWords $(\omega)$ in the sentence, each containing an accent. All four words are parsed into the $\mathrm{l}(\max )$, which parses the $\mathrm{CP} / v \mathrm{P}$, and there is a downstep between each accented PWord. Although it has no prosodic consequences, the head noun, when unmodified, is parsed into a recursive $\varphi$ with its sister DP. Note that we assume that not only the syntactically recursive argument XP but also the DPs/FPs it dominates are recursively parsed into $\varphi$.

In Type B sentences, the head noun is followed by an adjectival modifier. This leads to a different prosodic parse, disrupting the pattern of downstep-and of prosodic parsing. We assume, following Elordieta (2015, p. 63), that modified DPs disrupt the syntactically motivated mappings because they have a more complex syntactic structure than unmodified nouns. ${ }^{25}$ Note that the modified head noun is contained in an XP, which, moreover, consists of two PWords, thus satisfying the binary minimality condition on $\varphi$ (see (38)), just like the preceding DP, which also contains two PWords. Parsing each XP contained in the argument XP into a $\varphi$ thus yields a eurhythmic prosodic representation. The proposed prosodic parse is illustrated in (48): 
(48) Type B: $\quad\left[\left[[[\mathrm{N} \downarrow \mathrm{N}][\uparrow \mathrm{N} \downarrow \mathrm{A}]]_{\mathrm{DP}}[\downarrow \mathrm{V}]_{\mathrm{vP}}\right]_{\mathrm{vP}}\right]_{\mathrm{TP}}$

a. $\left.\left.\quad\left\{([([[\text { Mirénen }] \quad \downarrow \text { lagúnen }] \mathrm{DP}) \quad([\uparrow \text { libúru } \downarrow \text { lodídxak]FP })] \mathrm{DP}) \quad \downarrow[\text { gustaten } \mathrm{dxáraz}] \mathrm{VP}]_{\mathrm{vP}}\right\}\right]_{\mathrm{TP}}\right\}$ Miren-GEN.SG friend-GEN.PL book thick-ABS.PL like AUX 'I like Miren's friends' thick books.'

b.

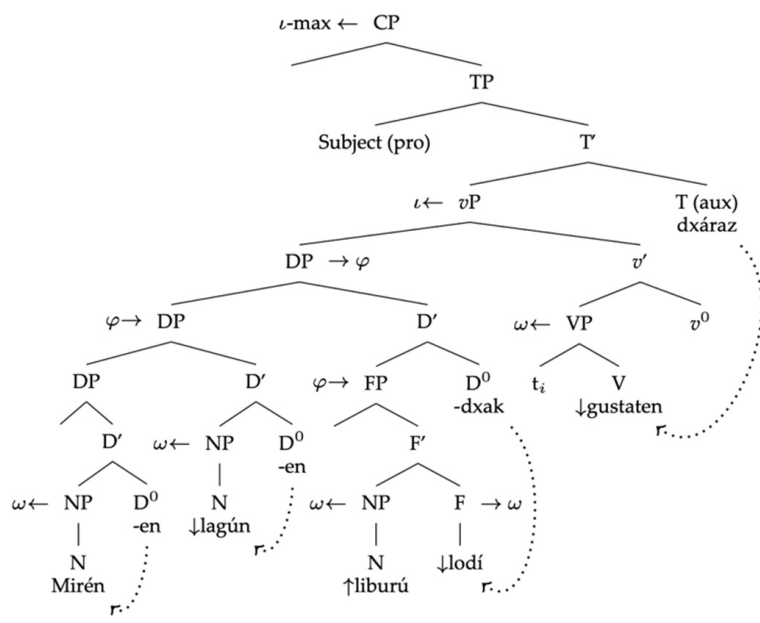

In the sentence in (48), there are five PWords but only three downsteps. Instead of the expected downstep preceding the head noun (liburú), there is an upstep/partial reset. We propose that the left edge of an $\iota_{\max }$ internal prosodic domain, in this case, $\varphi$, provides the triggering context for partial reset. Reset overrides the usual downstep that occurs between all accented PWords within $\iota_{\max }$ (the prosodic domain that correlates with the outermost phasal domain). ${ }^{26}$

In Type $C$ sentences, the third nominal is a second complement of the verb. As Elordieta (2015) observes, it is thus in a different syntactic relationship with the preceding nouns than in the Type A and B sentences:

(49) Type C: $\left[[\mathrm{N} \downarrow N]_{\mathrm{DP}}\left[[\uparrow N]_{\mathrm{DP}}[\downarrow \mathrm{V}]_{\mathrm{VP}}\right]_{\mathrm{VP}}\right]_{\mathrm{TP}}$

a. $\{([[$ Mirénen $) \quad \downarrow$ amúmari $] \mathrm{DP}) \quad\{[([\uparrow$ liburúak]DP $) \downarrow[$ emon dótzez $] \mathrm{VP}] \mathrm{vP}\}] \mathrm{TP}\}$ Miren-GEN.SG grandmother-DAT.SG book-ABS.PL give AUX

b.

'They have given the books to Miren's grandmother.'

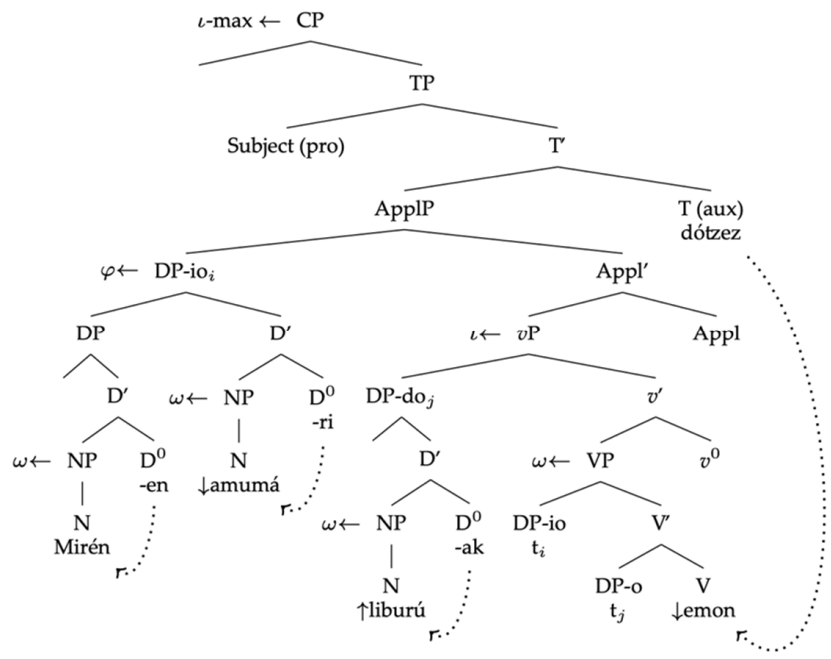

Mapping $v$ P to $\iota$ places a left $\iota$ boundary before the third noun, and, as expected, this left prosodic boundary triggers upstep/partial reset. ${ }^{27}$ Downsteps are found between the other PWords parsed into $\iota_{\max }$ :

Finally, in Type D sentences, the third noun is a verbal complement and also modified by an adjective. The analysis is essentially the same as for (49). Mapping $v \mathrm{P}$ to $\iota$ places a 
left $\iota$ boundary before the third noun and, as expected, this left prosodic boundary triggers upstep/partial reset. ${ }^{28}$ Downsteps are found between the other accented PWords parsed into $\mathrm{l}_{\max }$ :

(50) Type D: [[N $\left.\downarrow N]_{D P}\left[[\uparrow \uparrow N \downarrow A]_{D P}[\downarrow V] v P\right]_{v P}\right] \mathrm{TP}$

a. $\quad\{([[$ Mirénen $\downarrow$ amúmari $] \mathrm{DP}) \quad\{[([\uparrow \uparrow$ libúru $\downarrow$ lodídxak $] \mathrm{FP}) \downarrow[$ [emon dótzez] $] \mathrm{VP}] \mathrm{VP}\}] \mathrm{TP}\}$ Miren-GEN.SG grandmother-DAT.SG book thick-ABS.PL give AUX b. 'They have given the thick books to Miren's grandmother.'

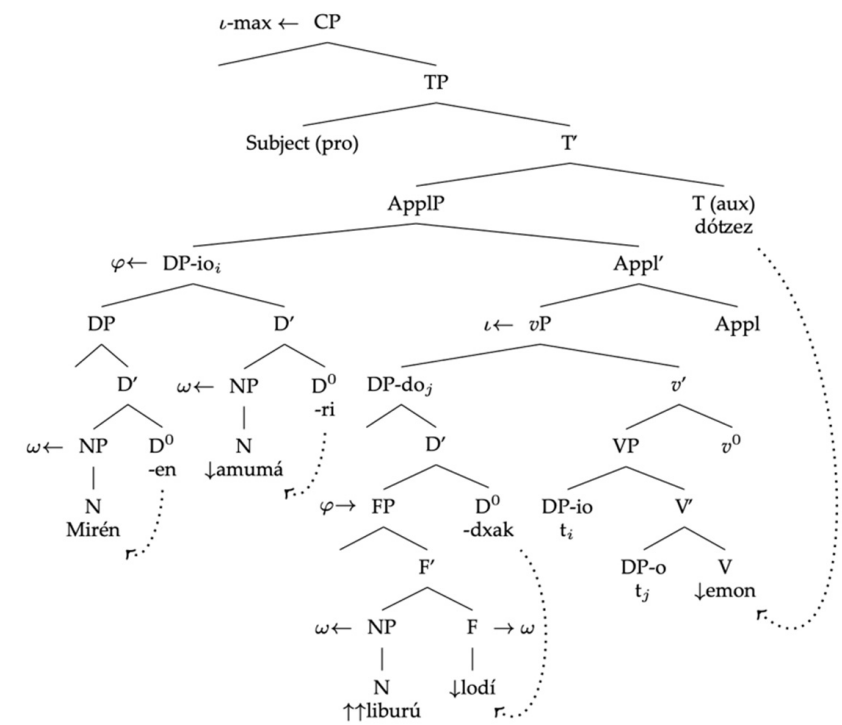

While this seems to be the most straightforward analysis of the generalizations in (46) based on the principles of the SPMH in (1) and (9), Elordieta (2015), like Elfner (2015), adopts an analysis that does not distinguish between $\varphi$ and ı. Rather, every XP, even if it is a phasal domain or even a root clause, is recursively parsed into a $\varphi$. This is illustrated by the prosodic parses Elordieta proposes for (48) and (49):

It is unclear what analytical or conceptual advantages this alternative parse provides compared to the disadvantages. Prosodic recursion does not mirror syntactic recursion (except in the case of genitive DP/NPs). Recall from the discussion in Section 2 that XP domination is not necessarily the equivalent of syntactic recursion, and so it does not provide a syntactic motivation for prosodic recursion. Furthermore, an entire clause is mapped to a recursive $\varphi$, in violation of core principles of the SPMH (1). CP is expected to map to I (see discussion of (9)), and the syntactic distinction between phrase and clause should be reflected in the prosodic structure. As noted in discussing Irish, an analysis in which recursions of $\varphi$ that map to phasal domains are instead mapped to เ yields a prosodic parse that better satisfies all of the principles of the SPMH in (1). It also allows for more consistent cross-linguistic generalizations about syntax-prosody correspondences and about the prosodic domain of intonational phenomena such as register reset. 

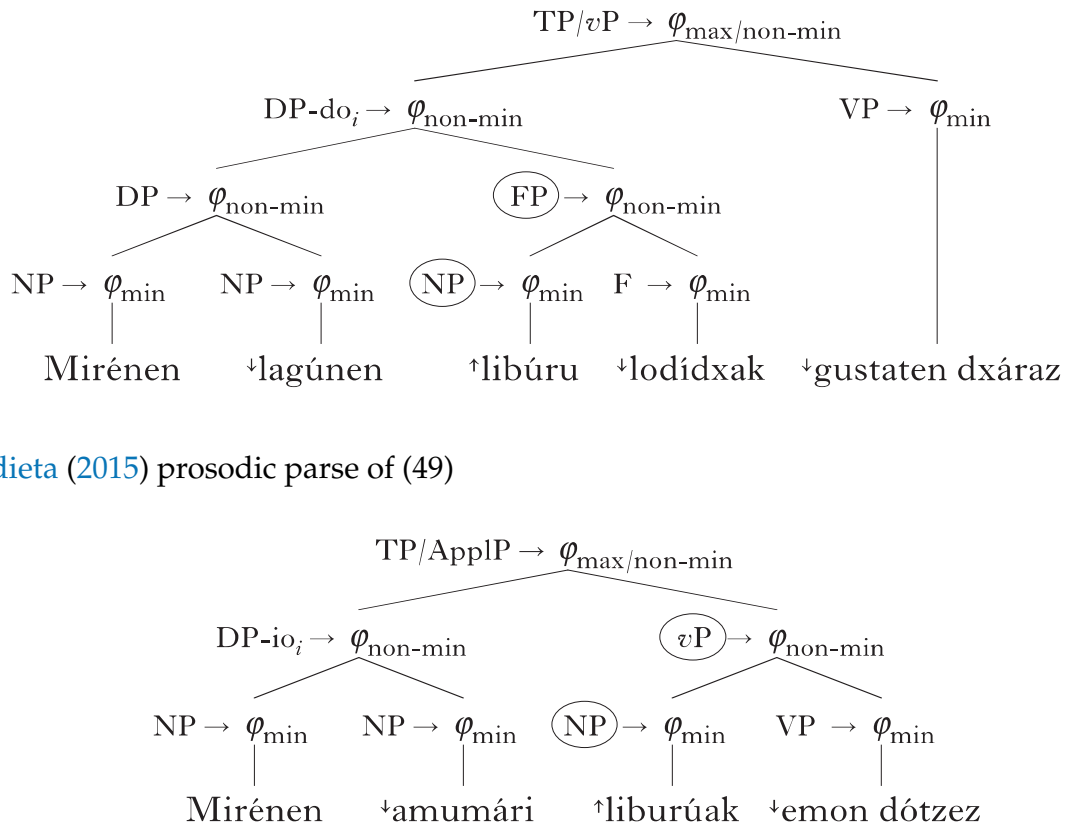

\section{Conclusions}

It is widely agreed that prosodic constituents should mirror syntactic constituents (unless high-ranking prosodic constraints interfere). Because recursion is a feature of syntactic representations, one expects recursion in prosodic representations as well, as work such as Féry (2016) and Selkirk (2011) has argued. Indeed, as we have shown, strictly respecting the requirement that the same types of prosodic constituent should correspond to the same types of syntactic constituent, both within a particular language and crosslinguistically, automatically leads to analyses where prosodic recursion is optimal when it mirrors syntactic recursion. While there are differing views concerning what kinds of syntactic representation motivate prosodic recursion, this paper has argued in favor of the restrictive view that prosodic recursion is motivated only if it mirrors syntactically defined embedded recursion, not other forms of syntactic domination.

To demonstrate the advantages of this approach, the use of Phonological Phrase recursion has been reviewed in several case studies, chosen because prosodic recursion in these studies mostly does not reflect syntactic recursion as defined in current syntactic theory. As we show, an approach that does not appeal to prosodic recursion (unless it is syntactically motivated) straightforwardly captures the relevant generalizations.

One of the forces driving analyses adopting recursive prosodic phrasing appears to be the desire to reduce the number of prosodic categories (Bennett and Elfner 2019; Ito and Mester 2013; Elfner 2015). Since the SPMH is founded on the principle that prosodic constituents reflect syntactic ones, it is striking that the drive to reduce the number of prosodic categories goes against recent syntactic theoretical trends such as the cartographic approach, which in fact creates more syntactic categories (starting with Topic and Focus). It should be noted that the additional syntactic categories do not come from a concern about reducing syntactic recursion. In other words, the number of categories and the licit use of recursion should not be connected issues. A final conceptual problem with a theory that allows prosodic recursion which is not motivated by syntactic recursion is that, as Schiering et al. (2010, p. 699) argue, if an unlimited number of intermediate recursions of, for example, a Phonological Phrase, is allowed by a theory, it makes prosodic recursion "too powerful and puts too [few] restrictions on prosodic systems", since intermediate prosodic recursions can parse groupings defined by language-particular syntactic structures 
rather than constituents with cross-linguistic syntactic motivation. Indeed, as van der Hulst (2010, p. 326) argues, languages do not seem to appeal to more than two recursions of any prosodic constituent. In syntax, too, Karlsson (2010) shows that it is rare to find more than two or three recursions in natural language. There are, then, many reasons to be leery of theories that do not place well-defined restrictions on possible recursive structures.

Finally, we propose that the more restrictive approach to prosodic recursion has the following advantages. It allows for more consistent cross-linguistic generalizations about the syntax-prosody mapping, so that prosodic representations more closely reflect syntactic ones. It allows the fundamental syntactic distinctions between clause, phase, and phrase to be reflected in the prosodic representation. It also allows cross-linguistic generalizations to be made about the prosodic domain of intonational processes such as register reset and continuation rise. The approach adopted here thus more closely respects all of the principles of the SPMH (1) and its underlying assumption that a theory that restrictively defines possible syntax-prosody correspondences is most likely to be of universal validity.

Author Contributions: Both authors have contributed equally to the analysis presented here. Both authors have read and agreed to the published version of the manuscript.

Funding: This research received no external funding.

Institutional Review Board Statement: Not applicable.

Informed Consent Statement: Not applicable.

Data Availability Statement: Not applicable.

Acknowledgments: The authors would like to thank the special issue editors and the reviewers for their comments and suggestions which improved the content and presentation of the proposals developed in the paper.

Conflicts of Interest: The authors declare no conflict of interest.

\section{Notes}

1 The traditional adjunction analysis yields iteration, in contrast with analyses à la Cinque (2010), with adjectives and adverbs generated in a functional projection above the NP and VP/vP respectively.

2 Note that the original Larsonian structure for double object sentences involve a passive-like transformation. See Citko et al. ( 2017) for discussion.

3 In both cases, there is embedding involved in the sense that the PP is embedded inside a VP, and the DP is embedded inside a PP. However, this type of embedding does not constitute recursion since VP and PP-like PP and DP-are not the same syntactic category.

4 See also articles in D'Alessandro et al. (2017) for discussions about the nature of the little $v$.

5 Whether or not it is the whole phase itself or the complement of a phase head being transferred at the point of spell-out is controversial. See Chomsky (2001), Bošković (2016), Cheng and Downing (2016), among others.

6 See Féry (2016) and Selkirk (2011) for detailed discussion of how recursive syntactic embedding as defined in (2), above, motivates recursive prosodic structure. Iterative recursion created by certain conjoined syntactic constructions also can lead to prosodic recursion; see Féry (2016), Ladd (1986, [1996] 2008) and Wagner (2005) for discussion.

$7 \quad$ We are ignoring $v$ P-phase here as it coincides with the CP-phase in these examples. It should also be noted that we do not claim that DP can never be a phase in any language. Nonetheless, evidence from Zulu suggests that DPs do not have phasal status, and thus do not trigger phasal spell-outs in Zulu.

8 See Selkirk (2011, 452ff) for detailed discussion of the distinction between the syntactic clause (CP) and the illocutionary clause or root clause, defined as the "highest syntactic projection of the sentence" (p. 452) (see, too, Selkirk 2005). Root CP is specified in $(13 c, d)$ to capture the generalization that the complements of verbs and restrictive relative clauses, which also are CP phases, typically phrase with their heads, as illustrated by Zulu examples in this section. That is, a right edge asymmetry holds except for the outermost recursion of $\mathrm{CP}$, i.e., the illocutionary clause.

9 Syntactic recursion does not lead to prosodic recursion in all languages. For example, Beltzung et al. (2010) show that there is no motivation for a right edge of $\mathrm{\iota}$ following relative clauses in Embosi. That is, in Embosi, the phrasing in (14b) is the correct output. This phrasing would be made optimal by ranking NORECURSION above ALIGNRPHASE. As Selkirk (2011) points out, it is this kind of cross-linguistic variation in the prosodic parse of the same syntactic structures that provides one of the strongest arguments for prosodic constraints on prosodic constituency mapping like NORECURSION. 
This also accounts for the High tone on the subject DP in (16b).

11 Underlining of certain consonants in the Chimwiini data indicates that they have dental place of articulation.

12 In Den Dikken (2007), $\Phi$ is used to indicate an extended phase. Here, we use $\gamma$, so as to not be confused with Greek letters that can be used to indicate Phonological Phrases. In the Bantu literature (including work by Cheng and Downing), an unspecified $X^{0}$ is used to indicate where the verb moves to and where the final vowel is hosted. Here, we replace this unspecified $X^{0}$ with $\gamma^{0}$ to reflect the extended phasal status of $X^{0}$.

13 See An (2007); Cheng and Downing (2016); Downing (2011); Feldhausen (2010); Féry (2011); Kula and Hamann (2017) and references therein for discussion of the phrasing of DPs in topic position, showing that it is common for them to be phrased separately from what follows.

14 Treating adjuncts as on a different plane comes from Chomsky (2004); see also analyses of adjuncts using Late Merge (Lebeaux 1988, Takahashi 2006 and Takahashi and Hulsey 2009), and other work on adjuncts such as Hunter (2010).

15 The data are mostly cited from Truckenbrodt (1995). However, we adapted the glosses and spellings to be closer to Odden (1987, 1996), following the suggestion of one of the reviewers. A cedilla under a high vowel indicates it is super-closed.

16 A reviewer questions whether the adverb pita 'really' has a preceding ı-boundary. Note that the interpretation of this adverb appears to be emphatic. We hypothesize that it is a focus adverb which takes the whole sentence as the focus. In other words, this adverb is not only a high adverb, it is a sentential adverb taking scope over the whole sentence. Unfortunately, a syntactic analysis does not exist for all the Kimatuumbi data in Odden's work, making it impossible for us to develop a prosodic analysis of a wider range of data than what is presented here.

17 Odden (1987) proposes this possibility but rejects it, among other reasons because recursion was not a well-formed property of prosodic parsing at the time he developed his analysis.

18 Similar points are made in work critiquing recursion at the PWord level, such as: Bickel et al. (2009); Downing and Kadenge ( 2020); Frota and Vigário (2013); Guzzo (2018); Schiering et al. (2010); Vigário (2010); and Vogel (2009, 2012, 2019).

19 In Hamlaoui and Makasso (2019), the verb moves from the lower V to the high V. In our analysis, which adapts theirs to current syntactic theory, the high $\mathrm{V}$ is a little $v$, which is a functional category and a phase head. Since Hamlaoui and Makasso (2019) do not indicate that the verb moves further than the higher $\mathrm{V}$ (i.e., the little $v$ ), we follow them in assuming that the end point of verb movement is at $v$. In other words, for Bàsàá, we do not assume an extended $v$ P phase.

20 As in Bàsàá (see Note 19), we do not have enough syntactic information to assume that the verb moves further than the little $v$. We therefore make the more conservative assumption that the verb only moves to the little $v$. Thus, $v \mathrm{P}$ is the phase.

21 In Akan and Bàsàá, unlike the other languages, STRONGSTART must be relatively low-ranked, as it appears to be optimal for material preceding the left edge of an $\iota_{\max }$-internal $\iota$ to remain weakly parsed, into a Phonological Phrase rather than an Intonation Phrase (Cf. discussion of (20a), above). We are crucially assuming that STRONGSTART is only relevant for the outermost $\iota$, the one that parses the illocutionary clause. It is worth pointing out that Elfner (2015) does not develop a complete formal analysis of the data discussed in this section.

As in the other languages discussed in this paper, verbs (including the [verb+aux $]_{V P}$ complex in Basque) are not necessarily parsed into a prosodic domain, rather only argument XPs are. We follow Féry (2011) in assuming the priority of argument XPs for prosodic parsing.

25 It has been observed at least since Nespor and Vogel (1986) that modified nouns can have a different prosodic parse than unmodified nouns. We have seen one example, above, in discussing Connemara Irish. Cheng and Downing (2016), Ghini (1993), Prieto (2005) and Selkirk (2011) review other examples. As Cheng and Downing (2016) note, even though the noun-modifier effect on phrasing appears to be common cross-linguistically, it is not clear that it has the same motivation in every language. We leave this as a topic for future research.

26 Our proposal partially echoes that of Jun and Elordieta (1997) and Selkirk (2011), which discuss a similar set of Basque data.

27 In Basque the verb stays in situ (see Elordieta 2015, among others) and the $v$ P remains as the phase; ApplP would therefore not constitute an extended phase. This contrasts with Chimwiini and other Bantu languages discussed above.

28 The double partial reset in $(50 a, b)$ is not accounted for in our analysis. We consider it a phonetic effect, induced by the extra length that results from adding another word following a partial reset at an $\iota_{\text {max }}$ internal ı boundary, (see Laniran and Clements 2003 for discussion of the effect of length on partial reset). We are skeptical of Elordieta (2015) claim that depth of prosodic embedding accounts for the degree of partial reset, as it seems unlikely that a single additional prosodic embedding should lead to five times greater amount of partial reset.

\section{References}

An, Duk-Ho. 2007. Clauses in Noncanonical Positions at the Syntax-Phonology Interface. Syntax 10: 38-79. [CrossRef] Beck, Sigrid, and Kyle Johnson. 2004. Double Objects Again. Linguistic Inquiry 35: 97-123. [CrossRef] 
Beltzung, Jean-Marc, Annie Rialland, and Martial Embanga Aborobongui. 2010. Les rélatives possessives enembosí (C25). In Papers from the Workshop on Bantu Relative Clauses. ZASPiL 53. Edited by Laura Downing, Annie Rialland, Jean-Marc Beltzung, Sophie Manus, Cédric Patin and Kristina Riedel. Berlin: ZAS, pp. 7-31.

Bennett, Ryan, and Emily Elfner. 2019. The syntax-prosody interface. Annual Review of Linguistics 5: 151-71. [CrossRef]

Bickel, Balthasar, Kristine A. Hildebrandt, and René Schiering. 2009. The distribution of phonological word domains: A probabilistic typology. In Phonological Domains: Universals and Deviations. Edited by Janet Grijzenhout and Baris Kabak. Berlin: Mouton de Gruyter, pp. 47-75. [CrossRef]

Bonet, Eulàlia, Lisa Lai-Shen Cheng, Laura J. Downing, and Joan Mascaró. 2019. (In)direct Reference in the Phonology-Syntax Interface under Phase Theory: A Response to "Modular PIC" (D'Alessandro and Scheer 2015). Linguistic Inquiry 50: 751-77. [CrossRef]

Bošković, Željko. 2014. Now I'm a phase, now I'm not a phase: On the variability of phases with extraction and ellipsis. Linguistic Inquiry 45: 27-89. [CrossRef]

Bošković, Željko. 2016. What is sent to spell-out is phases, not phasal complements. Linguistica 56: 25-66. [CrossRef]

Bresnan, Joan, and Sam A. Mchombo. 1987. Topic, pronoun, and agreement in Chicheŵa. Language 63: 741. [CrossRef]

Cheng, Lisa Lai-Shen, and Laura J. Downing. 2007. The prosody and syntax of relative clauses in Zulu. In Bantu in Bloomsbury: Special issue on Bantu Linguistics. SOAS WPL 15. Edited by Nancy C. Kula and Lutz Marten. London: SOAS, pp. 51-63.

Cheng, Lisa Lai-Shen, and Laura J. Downing. 2009. Where is the topic in Zulu? The Linguistic Review 26: 207-38. [CrossRef]

Cheng, Lisa Lai-Shen, and Laura J. Downing. 2016. Phasal syntax = cyclic phonology? Syntax 19: 156-91. [CrossRef]

Chomsky, Noam. 1995. The Minimalist Program. Cambridge: MIT Press.

Chomsky, Noam. 2000. Minimalist inquiries: The framework. In Step by Step. Edited by Roger Martin, David Michaels and Juan Uriagereka. Cambridge: MIT Press, pp. 89-155.

Chomsky, Noam. 2001. Derivation by phase. In Ken hale: A Life in Language. Edited by Michael Kenstowicz. Cambridge: M.I.T. Press, pp. $1-50$.

Chomsky, Noam. 2004. Beyond explanatory adequacy. In Structures and Beyond: The Cartography of Syntactic Structure. Edited by Adriana Belletti. Oxford: Oxford University Press, pp. 104-31.

Cinque, Guglielmo. 2010. The Syntax of Adjectives: A Comparative Study. Cambridge, MA: The MIT Press.

Citko, Barbara, Joseph Embley Emonds, and Rosemarie Whitney. 2017. Double object constructions. In The Wiley Blackwell Companion to Syntax, 2nd ed. Edited by Martin Everaert and Henk C. van Riemsdijk. Hoboken: John Wiley \& Sons, Inc., pp. 1-46.

Cowper, Elizabeth A., and Keren D. Rice. 1987. Are phonosyntactic rules necessary? Phonology Yearbook 4: 185-94. [CrossRef]

Cruttenden, Alan. 1981. Falls and rises: Meanings and universals. Journal of Linguistics 17: 77-91. [CrossRef]

D'Alessandro, Roberta, Irene Franco, and Ángel J. Gallego, eds. 2017. The Verbal Domain. Oxford: Oxford University Press. [CrossRef]

Dikken, Marcel den. 2007. Phase Extension Contours of a theory of the role of head movement in phrasal extraction. Theoretical Linguistics 33: 1-41. [CrossRef]

Downing, Laura J. 2011. The prosody of 'dislocation' in selected Bantu languages. Lingua 121: 772-86. [CrossRef]

Downing, Laura J., and Annie Rialland, eds. 2017. Intonation in African Tone Languages. Berlin: Mouton de Gruyter.

Downing, Laura J., and Maxwell Kadenge. 2020. Replacing PStem in the prosodic hierarchy. The Linguistic Review 37: 433-61. [CrossRef]

Elfner, Emily. 2015. Recursion in prosodic phrasing: Evidence from Connemara Irish. Natural Language E Linguistic Theory 33: 1169-208. [CrossRef]

Elordieta, Gorka. 2015. Recursive phonological phrasing in Basque. Phonology 32: 49-78. [CrossRef]

Epstein, Samuel David, Erich Groat, Ruriko Kawashima, and Hisa-tsugu Kitahara. 1998. A Derivational Approach to Syntactic Relations. New York: Oxford University Press.

Feldhausen, Ingo. 2010. Sentential Form and Prosodic Structure of Catalan. Amsterdam: Benjamins. [CrossRef]

Féry, Caroline. 2011. German sentence accents and embedded prosodic phrases. Lingua 121: 1906-22. [CrossRef]

Féry, Caroline. 2016. Intonation and Prosodic Structure. Cambridge: Cambridge University Press.

Frota, Sónia, and Marina Vigário. 2013. Review of Prosody Matters: Essays in honor of Elisabeth Selkirk. Phonology 30: 165-72. [CrossRef]

Gallego, Ángel J. 2010. Phase Theory. Amsterdam: John Benjamins Publishing Company. [CrossRef]

Ghini, Mirco. 1993. $\varphi$-formation in Italian: A new proposal. Toronto Working Papers in Linguistics 12: 41-79.

Guzzo, Natália Brambatti. 2018. The prosodic representation of composite structures in Brazilian Portuguese. Journal of Linguistics 54: 683-720. [CrossRef]

Hamlaoui, Fatima, and Emmanuel-Moselly Makasso. 2019. Downstep and recursive phonological phrases in Bàsàá (Bantu A43). In Theory and Description in African Linguistics: Selected Papers from the 47th Annual Conference on African Linguistics. Edited by Emily Clem, Peter Jenks and Hannah Sande. Berlin: Language Science Press, pp. 155-75. [CrossRef]

Hamlaoui, Fatima, and Kriszta Szendroï. 2015. A flexible approach to the mapping of intonational phrases. Phonology 32: 79-110. [CrossRef]

Hamlaoui, Fatima, Emmanuel-Moselly Makasso, and Siri M. Gjersøe. 2014. High tone spreading and phonological phrases in bàsàá. In 4th International Symposium on Tonal Aspects of Languages. Edited by C. Gussenhoven, Y. Chen and D. Dediu. Baixas: ISCA Archive, pp. 27-31. Available online: https://www.isca-speech.org/archive/tal_2014/papers/t114_027.pdf (accessed on 20 December 2020).

Harley, Heidi. 2002. Possession and the double object construction. Linguistic Variation Yearbook 2: 31-70. [CrossRef] 
Hunter, Timothy Andrew. 2010. Relating Movement and Adjunction in Syntax and Semantics. Doctoral dissertation, University of Maryland, College Park, MD, USA.

Inkelas, Sharon, and Draga Zec. 1995. Syntax-phonology interface. In The Handbook of Phonological Theory. Edited by John A. Goldsmith. Oxford: Blackwell, pp. 539-49.

Ishihara, Shinichiro. 2007. Major phrase, focus intonation and multiple spellout (MaP, FI, MSO). The Linguistic Review 24: 137-67. [CrossRef]

Ito, Junko, and Armin Mester. 2012. Recursive prosodic phrasing in Japanese. In Prosody Matters: Essays in Honor of Elisabeth Selkirk. Edited by Toni Borowsky, Sigeto Kawahara, Takahito Shinya and Mariko Sugahara. Sheffield: Equinox Publishing, pp. 280-303.

Ito, Junko, and Armin Mester. 2013. Prosodic subcategories in Japanese. Lingua 124: 20-40. [CrossRef]

Julien, Marit. 2002. Syntactic Heads and Word Formation. Oxford: Oxford University Press.

Jun, Sun-Ah, and Gorka Elordieta. 1997. Intonational structure of Lekeitio Basque. In Intonation: Theory, Models and Applications. Edited by Antonis Botinis, Georgios Kouroupetroglou and George Carayiannis. Athens: European Speech Communication Association, pp. 193-96.

Karlsson, Fred. 2010. Syntactic recursion and iteration. In Recursion and Human Language. Edited by Harry van der Hulst. Berlin and New York: De Gruyter Mouton, pp. 43-67. [CrossRef]

Kayne, Richard. 1994. The Antisymmetry of Syntax. Cambridge: MIT Press.

Kisseberth, Charles W. 2005. Accent and phrasing in Chimwiini. In Proceedings of the Symposium: Cross-linguistic Studies of Tonal Phenomena. Edited by S. Kaji. Tokyo: ILCAA, pp. 129-45.

Kisseberth, Charles W. 2010a. Optimality Theory and the theory of phonological phrasing: The Chimwiini evidence. In The Sound Patterns of Syntax. Edited by Nomi Erteschik-Shir and Lisa Rochman. Oxford: Oxford University Press, pp. $217-46$.

Kisseberth, Charles W. 2010b. Phrasing and relative clauses in Chimwiini. ZASPiL 53: 109-44. [CrossRef]

Kisseberth, Charles W. 2017. Chimiini intonation. In Intonation in African Tone Languages. Edited by Laura J. Downing and Annie Rialland. Berlin and Boston: De Gruyter, pp. 225-84. [CrossRef]

Kratzer, Angelika, and Elisabeth Selkirk. 2007. Phase theory and prosodic spellout: The case of verbs. The Linguistic Review 24: 93-135. [CrossRef]

Kügler, Frank. 2015. Phonological phrasing and ATR vowel harmony in Akan. Phonology 32: 177-204. [CrossRef]

Kügler, Frank. 2017. Tone and intonation in Akan. In Intonation in African Tone Languages. Edited by Laura J. Downing and Annie Rialland. Berlin and Boston: De Gruyter, pp. 89-130.

Kula, Nancy C., and Silke Hamann. 2017. Intonation in Bemba. In Intonation in African Tone Languages. Edited by Laura J. Downing and Annie Rialland. Berlin and Boston: De Gruyter, pp. 321-64. [CrossRef]

Ladd, D. Robert. 1986. Intonational phrasing: The case for recursive prosodic structure. Phonology Yearbook 3: 311-40. [CrossRef]

Ladd, D. Robert. 2008. Intonational Phonology. Cambridge: Cambridge University Press. First published 1996.

Laniran, Yetunde O., and G. N. Clements. 2003. Downstep and high raising: Interacting factors in Yoruba tone production. Journal of Phonetics 31: 203-50. [CrossRef]

Larson, Richard. 1988. On the double object construction. Linguistic Inquiry 19: 335-91.

Lebeaux, David. 1988. Language Acquisition and the Form of the Grammar. Doctoral dissertation, University of Massachusetts, Amherst, MA, USA.

McCarthy, John J., and Alan Prince. 1986. Prosodic Morphology 1986. Linguistics Department Faculty Publication Series 13. Available online: https: / / scholarworks.umass.edu/linguist_faculty_pubs/13 (accessed on 7 July 2021).

Nespor, Marina, and Irene Vogel. 1986. Prosody Phonology. Dordrecht: Foris Publications.

Nevins, Andrew, David Pesetsky, and Cilene Rodrigues. 2009. Pirahã exceptionality: A reassessment. Language 85: 355-404. [CrossRef]

Odden, David. 1987. Kimatuumbi phrasal phonology. Phonology Yearbook 4: 13-36. [CrossRef]

Odden, David. 1990. Syntax, lexical rules, and postlexical rules in Kimatuumbi. In The Phonology-Syntax Connection. Edited by Sharon Inkelas and Draga Zec. Chicago: University of Chicago Press, pp. 259-78.

Odden, David. 1996. The Phonology and Morphology of Kimatuumbi. Oxford: Oxford University Press.

Prieto, Pilar. 2005. Syntactic and eurythmic constraints on phrasing decisions in Catalan. Studia Linguistica 52: 194-222. [CrossRef]

Sande, Hannah, Peter Jenks, and Sharon Inkelas. 2020. Cophonologies by Ph(r)ase. Natural Language and Linguistic Theory 38: $1211-61$. [CrossRef]

Schiering, René, Balthasar Bickel, and Kristine A. Hildebrandt. 2010. The prosodic word is not universal, but emergent. Journal of Linguistics 46: 657-709. [CrossRef]

Selkirk, Elisabeth O. 1986. On derived domains in sentence phonology. Phonology 3: 371-405. [CrossRef]

Selkirk, Elisabeth O. 1995. The prosodic structures of function words. UMOP 18: 439-69.

Selkirk, Elisabeth O. 2000. The interaction of constraints on prosodic phrasing. In Prosody: Theory and Experiment. Edited by Merle Horne. Dordrecht: Kluwer, pp. 231-61.

Selkirk, Elisabeth O. 2005. Comments on Intonational Phrasing in English. In Prosodies: With Special Reference to Iberian Languages. Edited by Sonia Frota, Marina Vigário and Maria João Freitas. Berlin: Mouton de Gruyter, pp. 11-58.

Selkirk, Elisabeth O. 2009. On clause and intonational phrase in Japanese: The syntactic grounding of prosodic constituent structure. Gengo Kenkyuu 136: 35-73. 
Selkirk, Elisabeth O. 2011. The syntax-phonology interface. In The Handbook of Phonological Theory, 2nd ed. Edited by John Goldsmith, Jason Riggle and Alan C. L. Yu. Oxford: Wiley-Blackwell, pp. 435-84. [CrossRef]

Takahashi, Shoichi, and Sarah Hulsey. 2009. Wholesale late merger: Beyond the A/Ā distinction. Linguistic Inquiry 40: 387-426. [CrossRef]

Takahashi, Shoichi. 2006. Decompositionality and Identity. Doctoral dissertation, M.I.T., Cambridge, MA, USA.

Truckenbrodt, Hubert. 1995. Phonological phrases: Their relation to syntax, focus and prominence. Doctoral Dissertation, M.I.T., Cambridge, MA, USA

Truckenbrodt, Hubert. 1999. On the relation between syntactic phrases and phonological phrases. Linguistic Inquiry 30: 219-55. [CrossRef]

Truckenbrodt, Hubert. 2007. The syntax-phonology interface. In The Cambridge Handbook of Phonology. Edited by Paul de Lacy. Cambridge: Cambridge University Press, pp. 435-56.

Uriagereka, Juan. 1999. Multiple Spell-Out. In Working minimalism. Edited by Samuel David Epstein and Norbert Hornstein. Cambridge: MIT Press, pp. 251-82.

Van der Hulst, Harry, ed. 2010. A note on recursion in phonology. In Recursion and Human Language. Berlin and New York: De Gruyter Mouton, pp. 301-41. [CrossRef]

Vigário, Marina. 2010. Prosodic structure between the prosodic word and the phonological phrase: Recursive nodes or an independent domain? The Linguistic Review 27: 485-530. [CrossRef]

Vogel, Irene. 2009. Universals of prosodic structure. In Universals of Language Today. Edited by Sergio Scalise, Elisabetta Magni and Antonietta Bisetto. Dordrecht: Springer, pp. 59-82.

Vogel, Irene. 2012. Recursion in phonology? In Phonological Explorations: Empirical, Theoretical and Diachronic Issues. Edited by Bert Botma and Roland Noske. Berlin: De Gruyter, pp. 41-61. [CrossRef]

Vogel, Irene. 2019. Life after the Strict Layer Hypothesis. In Prosodic Studies: Challenges and Prospects. Edited by Hongming Zhang. London: Routledge, pp. 9-60.

Wagner, Michael. 2005. Prosody and recursion. Doctoral Dissertation, M.I.T., Cambridge, MA, USA. 